GLOBAL WATER PATHOGEN PROJECT

PART THREE. SPECIFIC EXCRETED PATHOGENS: ENVIRONMENTAL AND EPIDEMIOLOGY ASPECTS

\title{
CYCLOSPORA CAYETANENSIS
}

Leonor Chacin-Bonilla

Universidad del Zulia: Inicio

Maracaibo, Venezuela 


\section{Copyright:}

\section{cc) (i) (2) \\ BY SA}

This publication is available in Open Access under the Attribution-ShareAlike 3.0 IGO (CC-BY-SA 3.0 IGO) license (http://creativecommons.org/licenses/by-sa/3.0/igo). By using the content of this publication, the users accept to be bound by the terms of use of the UNESCO Open Access Repository (http://www.unesco.org/openaccess/terms-use-ccbysa-en).

\section{Disclaimer:}

The designations employed and the presentation of material throughout this publication do not imply the expression of any opinion whatsoever on the part of UNESCO concerning the legal status of any country, territory, city or area or of its authorities, or concerning the delimitation of its frontiers or boundaries. The ideas and opinions expressed in this publication are those of the authors; they are not necessarily those of UNESCO and do not commit the Organization.

\section{Citation:}

Chacin-Bonilla, L. (2017). Cyclospora Cayetanensis. In: J.B. Rose and B. Jiménez-Cisneros, (eds) Water and Sanitation for the 21st Century: Health and Microbiological Aspects of Excreta and Wastewater Management (Global Water Pathogen Project). (R. Fayer and W. Jakubowski (eds), Part 3: Specific Excreted Pathogens: Environmental and Epidemiology Aspects - Section 3: Protists), Michigan State University, E. Lansing, MI, UNESCO. https://doi.org/10.14321/waterpathogens.32

Acknowledgements: K.R.L. Young, Project Design editor; Website Design: Agroknow (http:// www.agroknow.com)

Last published: March 15, 2017 


\section{Summary}

Cyclospora cayetanensis is recognized as an emerging protist that causes diarrheal illness and significantly contributes to the burden of gastroenteritis worldwide. This chapter summarizes the current status of knowledge of the parasite focusing on its public health impact and control strategies. Challenges and limitations for controlling the parasite are discussed.

Cyclospora cayetanensis is an apicomplexan coccidium in the family Eimeriidae closely related to Eimeria species. The parasite is endemic in tropical areas but reported worldwide. Humans are the only hosts known. Cyclospora is responsible for significant morbidity in children and AIDS patients and an important cause of foodborne outbreaks. Young children, older adults, and the immunocompromised are more susceptible to disease.

Globalization of the food supply and increased world travel have contributed to the spread of the parasite to nonendemic areas. Most of the cases have been linked with travelers or foodborne outbreaks. Berries and leafy green vegetables have been implicated as food sources. Consumption of fruits and raw vegetables, drinking untreated water, swimming in rivers, contact with soil or animals, agricultural occupation, and no hand washing have been associated with infection. Cyclospora has been isolated from fruits, vegetables, shellfish, drinking water, swimming pools, lakes, rivers, wastewater, sewage water, and soil. The oocysts are highly resistant to environmental conditions, pesticides, and disinfectants.

Cyclospora oocysts can be identified using microscopy, and molecular methods. Techniques for fingerprinting analysis and genotype discrimination are not available. The lack of an animal model and limited DNA sequence data have hampered efforts to develop detection methods. The complete apicoplast and mitochondrial genomes of $C$. cayetanensis were recently obtained which could facilitate the development of genotyping tools.

Prevention and control measures include improvement of personal hygiene, efficient sanitation, and improved water quality management. Food safety training worldwide is necessary. Quantifying risk and controlling Cyclospora in the environment are complicated by the low infectious dose, the highly resistant oocysts, and the longer sporulation and pre-patent periods.

\section{Cyclospora cayetanensis}

Cyclospora cayetanensis is the only known species of the genus Cyclospora to infect humans. Infection results in enteric disease, primarily diarrhea, but asymptomatic infection has been observed. This protozoan parasite is a fecal-oral pathogen in which the oocyst from excreta must mature in the environment (eg sewage, water or soil) to become infectious. About $40 \%$ of oocysts sporulate and become infectious within 14 days at temperatures between 23 and $32^{\circ} \mathrm{C}$ (Ortega et al., 1994) To date no animal reservoir hosts are known. Transmission appears to be primarily foodborne through fresh fruits and vegetables although contact with human fecally contaminated irrigation water, drinking water, recreational water, sewage, and soil has been documented. Exposure to $C$. cayetanensis in non- endemic locations has increased in parallel with the globalization of the food supply, increased consumption of fresh foods, human migration, and increased world travel. The opening of new markets for fresh fruits and vegetables from endemic areas where crops are grown has transformed food consumption patterns resulting in consumption of raw or undercooked foods potentially exposing consumers to pathogenic contaminants including $C$. cayetanensis. Seasonal variation in the prevalence of cyclosporiasis may be influenced by factors such as rainfall, temperature, and humidity. Climate change is likely to influence the exposure to the parasite.

Water sanitation is essential to control the transmission of cyclosporiasis in both developed and developing countries as well as improved hygiene associated with food safety. A better global understanding of this parasite and the hazard analysis and critical control points (HACCP) arrangements could play a significant role in the control of Cyclospora (Buisson et al., 2008). In industrialized countries, surveillance of foodborne diseases has become a fundamental component of food safety systems (Gervelmayer et al., 2008).

\subsection{Epidemiology of the Disease and Pathogen}

\subsection{Global Burden of Disease}

\subsubsection{Global distribution}

Cyclospora cayetanensis infection has been found worldwide, in developed and developing countries and in urban and rural areas but is most common in tropical and subtropical areas (Ortega, 1998). The first documented cases were found in Papua, New Guinea in 1977 and 1978 (Ashford, 1979).

In endemic countries, large-scale surveillance studies of apparently immunocompetent individuals have reported Cyclospora infection rates from 0 to $41.6 \%$ (Table1). In immunocompromised patients, mostly HIV/AIDS patients with diarrhea, the percentages of Cyclospora infections have ranged from 0 to $36 \%$ (Chacin-Bonilla et al., 2001, 2006, 2010). In Colombia, Saudi Arabia, Malaysia, Tanzania, and Cameroon, infection rates of 2.6, 5.9, 4.9, 1.2 , and $3.6 \%$, respectively, have been found (Arzuza et al., 2003; Al-Megrin, 2010; Asma et al., 2011; Cegielski et al. 1999; Nsagha et al., 2016).Variations in prevalence of infection may be influenced by study design, geographic area, age, and immunologic status of the population studied, seasonal variability of the parasite, methods of detection used, and expertise of the microscopist. 
Table 1. Selected reports of Cyclospora prevalence in immunocompetent individuals from developing countries

\begin{tabular}{|c|c|c|c|}
\hline Area & Population & $\begin{array}{c}\text { Infected Percentage } \\
\text { (\# of samples) }\end{array}$ & Reference \\
\hline Bangladesh & 2 to $5 \mathrm{yr}$ & $\begin{array}{c}0 \% \\
(0 / 289)\end{array}$ & Haque et al., 2003 \\
\hline Brazil & All ages & $\begin{array}{l}10.8 \% \\
(9 / 83)\end{array}$ & Días-Borges et al., 2009 \\
\hline China & All ages & $\begin{array}{c}5.6 \% \\
(10 / 178)\end{array}$ & Wang et al., 2002 \\
\hline China & Children & $\begin{array}{c}0 \% \\
(0 / 252)^{\mathrm{a}}\end{array}$ & Liu et al., 2014 \\
\hline Cuba & 0 to $7 \mathrm{yr}$ & $\begin{array}{c}4.4 \% \\
(5 / 113)\end{array}$ & Nuñez et al., 2003 \\
\hline Egypt & All ages & $\begin{array}{c}9.2 \% \\
(12 / 130)\end{array}$ & Nassef et al., 1998 \\
\hline Guatemala & All ages & $\begin{array}{c}2.3 \% \\
(126 / 5,552)\end{array}$ & Bern et al., 1999 \\
\hline Guatemala & Farm families $^{\mathrm{b}}$ & $\begin{array}{c}3.3 \% \\
(6 / 182)\end{array}$ & Bern et al., 1999 \\
\hline Haiti & All ages & $\begin{array}{c}6.0 \% \\
(24 / 402)\end{array}$ & López et al., 2003 \\
\hline Honduras & All ages & $\begin{array}{c}2 \% \\
(96 / 4,698)\end{array}$ & Kaminsky, 2002 \\
\hline India & All ages & $\begin{array}{c}10.6 \% \\
(33 / 310)\end{array}$ & Gupta, 2011 \\
\hline Indonesia & School children & $\begin{array}{c}0.6 \% \\
(2 / 348)\end{array}$ & Fryauff et al., 1999 \\
\hline Jordan & All ages & $\begin{array}{c}6 \% \\
(12 / 200)\end{array}$ & Nimri, 2003 \\
\hline Lao PDR & All ages & $\begin{array}{c}0.1 \% \\
(1 / 686)\end{array}$ & Kimura et al., 2005 \\
\hline Mexico & Children & $\begin{array}{c}3.3 \% \\
(9 / 272)\end{array}$ & Díaz et al., 2003 \\
\hline Mexico & Children & $\begin{array}{c}0.6 \% \\
(60 / 8,877)\end{array}$ & Orozco-Mosqueda, 2014 \\
\hline Morocco & School children & $\begin{array}{c}3.3 \% \\
(22 / 673)\end{array}$ & El Fatni, 2014 \\
\hline Nepal & All ages & $\begin{array}{c}9.2 \% \\
(128 / 1,397)\end{array}$ & Kimura et al., 2005 \\
\hline Nepal & School children & $\begin{array}{c}1.6 \% \\
(23 / 1,392)\end{array}$ & Tandukar et al., 2013 \\
\hline Nepal & School children & $\begin{array}{c}3.9 \% \\
(20 / 507)\end{array}$ & Bhandari et al., 2015 \\
\hline Nigeria & All ages & $\begin{array}{c}1 \% \\
(11 / 1,109)\end{array}$ & Alakpa et al., 2003 \\
\hline Peru & 0 to $2.6 \mathrm{yr}$ & $\begin{array}{c}10.9 \% \\
(41 / 377)\end{array}$ & Ortega et al., 1993 \\
\hline Peru & Children & $\begin{array}{c}1.1 \% \\
(63 / 5,836)\end{array}$ & Madico et al., 1997 \\
\hline Peru & All ages & $\begin{array}{c}41.6 \% \\
(121 / 291)\end{array}$ & Burstein Alva, 2005 \\
\hline Peru & Adults & $\begin{array}{c}4.3 \% \\
(11 / 256)\end{array}$ & Roldán et al., 2009 \\
\hline Saudi Arabia & $<5 \mathrm{yr}$ & $\begin{array}{l}11.1 \% \\
(7 / 63)\end{array}$ & Al-Braiken et al., 2003 \\
\hline Thailand & All ages & $\begin{array}{c}0.5 \% \\
(12 / 2,540)^{\mathrm{a}}\end{array}$ & Thima et al., 2014 \\
\hline
\end{tabular}




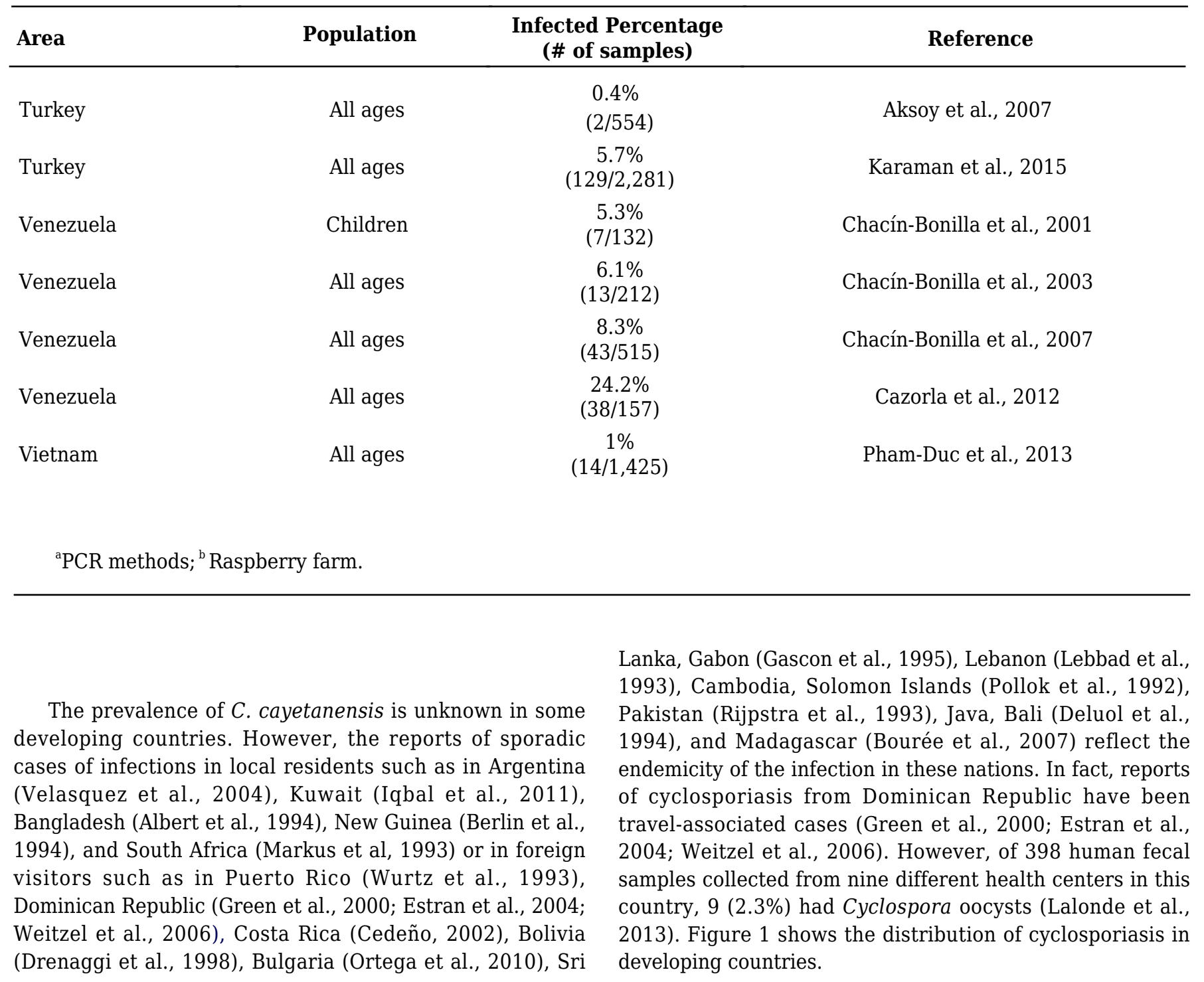
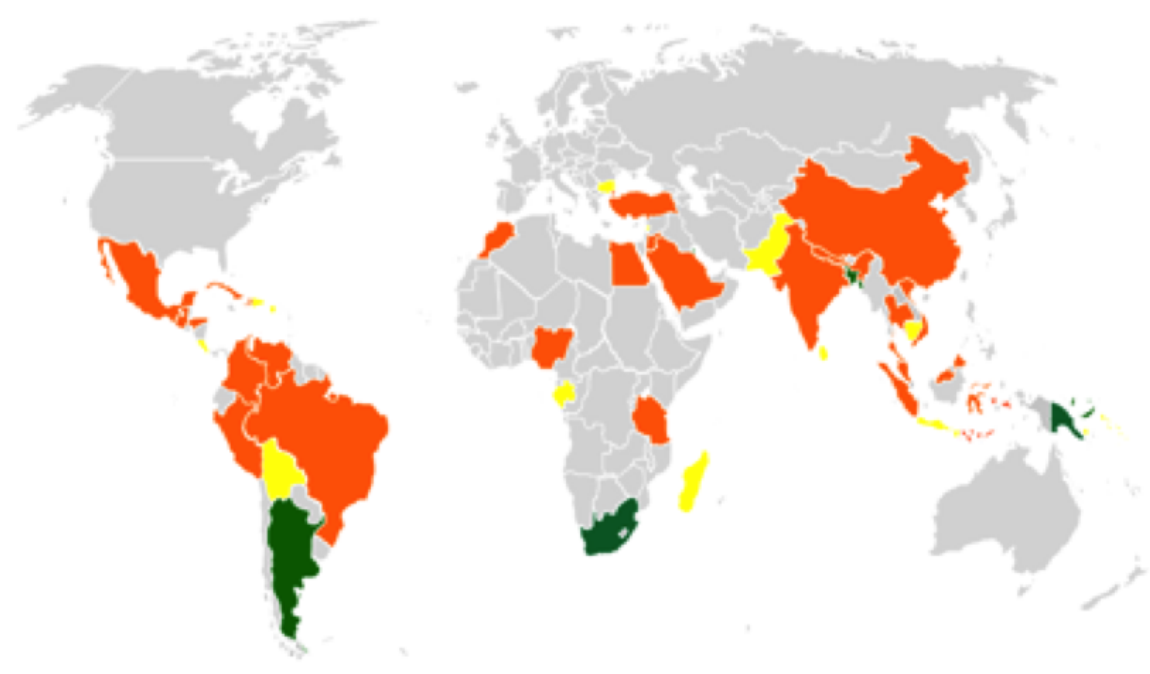

Figure 1. Distribution of cyclosporiasis in developing regions: countries that have reported infection-endemic areas (orange), infection cases without travel history (green), or have been visited by travelers that acquired infection (yellow) 
Cyclosporiasis has been found to be common in children in endemic areas. They are often asymptomatic or have relatively mild illness (Madico et al., 1997; Ortega et al., 1997a; Eberhard et al., 1999b; Chacín-Bonilla et al., 2003, 2007). High percentages of asymptomatic carriers (68.2-98.7\%, average $87.1 \%$ ) have been noted in community-based surveys (Chacin-Bonilla, 2010; Bhandari et al., 2015); in some studies, up to $100 \%$ of infected children were asymptomatic (Thima et al., 2014), suggesting a development of immune protection from disease but not infection. Thus, in endemic settings, $C$. cayetanensis may not play a consistently pathogenic role. It appears that in these areas, the situation at the general population level is quite different than that observed in children that attended health centers in whom a strong association of the parasite with diarrhea has been recognized (Zerpa et al., 1995; Fryauff et al., 1999; AlBraiken et al., 2003; Nuñez et al., 2003; Mansfield and Gajadha, 2004). This may be related to the risk of exposure from shared foods and water. This finding suggests that cyclosporiasis is common in impoverished areas where water and food sanitation are poor or nonexistent. It may be that very early and persistent exposure may be associated with immunity to illness and asymptomatic excretion (Madico et al., 1997; Ortega et al., 1997a; Bern et al., 2002). In fact, after an initial episode of cyclosporiasis, the likelihood of diarrhea and duration of symptoms decreases significantly with each subsequent infection (Bern et al., 2002).

Outbreaks of cyclosporiasis have also been reported among local populations and foreign residents or visitors in the developing world (Shlim et al., 1991; Hoge et al., 1993; Rabold et al., 1994). Table 2 shows epidemics that occurred in the 2000s. The explanation for the epidemics in local adult populations is that acquired immunity in these areas is not long lasting and fades over time (Torres-Slimming et al., 2006) or that geographic distribution, prevalence, and spread of the parasite in one region may vary from one place to another leaving some populations unprotected, particularly those from the upper social class (Mundaca et al., 2008). The limited outbreaks of cyclosporiasis reported in endemic areas could be the indiscriminate use of antibiotics effective against $C$. cayetanensis and the lack of adequate diagnostic capability (Torres-Slimming et al., 2006).

Table 2. Worldwide Cyclospora outbreaks: 2000-2015

\begin{tabular}{|c|c|c|c|c|c|}
\hline Area & Date & No. of Cases ${ }^{a}$ & Vehicle & Origin & Reference \\
\hline $\begin{array}{l}\text { Australian } \\
\text { cruise ship: } \\
\text { Fremantle } \\
\text { departure }\end{array}$ & $\begin{array}{c}2010 \\
\text { May-Jun }\end{array}$ & $266^{\mathrm{b}}$ & Lettuce $^{\mathrm{c}}$ & Malaysia $^{c}$ & $\begin{array}{c}\text { Gibbs et al., } \\
2013\end{array}$ \\
\hline Canada $(B C)^{d}$ & $\begin{array}{l}2001 \\
\text { May }\end{array}$ & 17 & Thai basil & USA & $\begin{array}{l}\text { Hoang et al., } \\
2005\end{array}$ \\
\hline Canada (BC) & $2003 \mathrm{Jul}$ & 11 & Cilantro $^{\mathrm{C}}$ & $\mathrm{UD}^{\mathrm{e}}$ & $\begin{array}{c}\text { Kozak et al., } \\
2013\end{array}$ \\
\hline Canada (BC) & 2004 & 17 & $\begin{array}{c}\text { Mango, } \\
\text { basil }^{\mathrm{c}}\end{array}$ & UD & $\begin{array}{l}\text { Kozak et al., } \\
2013\end{array}$ \\
\hline Canada (BC) & $\begin{array}{c}2004 \\
\text { May-Jun }\end{array}$ & 8 & Cilantro $^{c}$ & UD & PHAC $^{\mathrm{f}}, 2006$ \\
\hline Canada (BC) & $\begin{array}{c}2006 \\
\text { Jun-Jul }\end{array}$ & 28 & $\begin{array}{l}\text { Basil or } \\
\text { garlic }\end{array}$ & UD & $\begin{array}{c}\text { Kozak et al., } \\
2013\end{array}$ \\
\hline Canada (BC) & $\begin{array}{c}2007 \\
\text { May-Aug }\end{array}$ & 29 & Basil & Mexico & $\begin{array}{c}\text { Shah et al., } \\
2009\end{array}$ \\
\hline $\begin{array}{l}\text { Canada } \\
\text { (Ontario) }\end{array}$ & $\begin{array}{c}2005 \\
\text { Apr }\end{array}$ & 44 & Basilc & UD & $\begin{array}{l}\text { Kozak et al., } \\
2013\end{array}$ \\
\hline $\begin{array}{l}\text { Canada } \\
\text { (Quebec) }\end{array}$ & $2005 \mathrm{Jul}$ & 200 & Basil & Mexico & PHAC, 2007 \\
\hline Canadag & $\begin{array}{c}2015 \\
\text { May-Aug }\end{array}$ & 97 & UD & UD & PHAC, 2015 \\
\hline $\begin{array}{l}\text { Colombia } \\
\text { (Medellin) }\end{array}$ & $\begin{array}{c}2002 \\
\text { Apr }\end{array}$ & 31 & $\begin{array}{l}\text { Salads, } \\
\text { juice }\end{array}$ & UD & $\begin{array}{c}\text { Botero-Garcés } \\
\text { et al., } 2006\end{array}$ \\
\hline $\begin{array}{l}\text { Cruise ship } \\
\text { (Several } \\
\text { countries) }\end{array}$ & $\begin{array}{c}2009 \\
\text { Apr }\end{array}$ & 160 & UD & UD & CDC, 2009 \\
\hline Germany & $\begin{array}{l}2000 \\
\text { Dec }\end{array}$ & 34 & $\begin{array}{l}\text { Salads, } \\
\text { herbs }\end{array}$ & $\begin{array}{l}\text { France, } \\
\text { Italy, } \\
\text { Germany }\end{array}$ & $\begin{array}{l}\text { Doller et al., } \\
2002\end{array}$ \\
\hline $\begin{array}{l}\text { Indonesia } \\
\text { (Bangor) }\end{array}$ & $\begin{array}{l}2001 \\
\text { Sep }\end{array}$ & 14 & UD & UD & $\begin{array}{c}\text { Blans et al., } \\
2005\end{array}$ \\
\hline
\end{tabular}




\begin{tabular}{|c|c|c|c|c|c|}
\hline Area & Date & No. of Cases ${ }^{a}$ & Vehicle & Origin & Reference \\
\hline $\begin{array}{l}\text { Mexico } \\
\text { (Monterrey) }\end{array}$ & $\begin{array}{c}2001 \\
\text { Apr }\end{array}$ & 97 & Watercress & UD & $\begin{array}{c}\text { Ayala-Gaytán et } \\
\text { al., } 2004\end{array}$ \\
\hline Peru (Lima) & $\begin{array}{l}2004 \\
\text { Nov }\end{array}$ & 127 & UD & UD & $\begin{array}{l}\text { Torres-Slimming } \\
\text { et al., } 2006\end{array}$ \\
\hline Peru (Lima) & $\begin{array}{l}2005 \\
\text { Mar }\end{array}$ & 37 & UD & UD & $\begin{array}{c}\text { Mundaca et al., } \\
2008\end{array}$ \\
\hline Poland & $\begin{array}{l}2013 \\
\text { Nov }\end{array}$ & $3^{\mathrm{h}}$ & $\begin{array}{l}\text { Drinking } \\
\text { water }\end{array}$ & Indonesia & $\begin{array}{l}\text { Bednarska et } \\
\text { al., } 2015\end{array}$ \\
\hline $\begin{array}{l}\text { Spain } \\
\text { (Madrid) }\end{array}$ & $\begin{array}{l}2003 \\
\text { May }\end{array}$ & $11^{\mathrm{h}}$ & $\begin{array}{l}\text { Raspberry } \\
\text { juice }\end{array}$ & Guatemala & $\begin{array}{l}\text { Puente et al., } \\
2006\end{array}$ \\
\hline $\begin{array}{l}\text { Sweden } \\
\text { (Stockholm) }\end{array}$ & $\begin{array}{l}2009 \\
\text { May-Jun }\end{array}$ & 18 & Snaps peas & Guatemala & $\begin{array}{l}\text { Insulander et } \\
\text { al., } 2010\end{array}$ \\
\hline Turkey (Izmir) & $\begin{array}{l}2005 \\
\text { Sep }\end{array}$ & 19 & $\begin{array}{c}\text { Drinking } \\
\text { water }\end{array}$ & UD & $\begin{array}{l}\text { Aksoy et al., } \\
2007\end{array}$ \\
\hline $\begin{array}{l}\text { Turkey } \\
\text { (Istanbul) }\end{array}$ & $\begin{array}{l}2007 \\
\text { Jul-Aug }\end{array}$ & 286 & UD & UD & $\begin{array}{c}\text { Ozdamar et al., } \\
2008\end{array}$ \\
\hline $\begin{array}{l}\text { United } \\
\text { Kingdom }^{g}\end{array}$ & $\begin{array}{l}2015 \\
\text { Jun-Sep }\end{array}$ & $79^{\mathrm{h}}$ & UD & Mexico & $\begin{array}{c}\text { Nichols et al., } \\
2015\end{array}$ \\
\hline $\begin{array}{l}\text { USA } \\
\text { (Pennsylvania) }\end{array}$ & $\begin{array}{l}2000 \\
\text { Jun }\end{array}$ & 54 & $\begin{array}{l}\text { Raspberry } \\
\text { cake }\end{array}$ & Guatemala & Ho et al., 2002 \\
\hline $\begin{array}{l}\text { USA (Texas, } \\
\text { Illinois) }\end{array}$ & $\begin{array}{l}2004 \\
\text { Feb }\end{array}$ & 95 & UD & UD & $\begin{array}{l}\text { Ortega et al., } \\
2010\end{array}$ \\
\hline $\begin{array}{l}\text { USA } \\
\text { (Pennsylvania) }\end{array}$ & $\begin{array}{c}2004 \\
\text { Jun-Jul }\end{array}$ & 96 & Snow peas & Guatemala & CDC, 2004 \\
\hline USA (Florida) & $\begin{array}{c}2005 \\
\text { Apr }\end{array}$ & 592 & Basil & UD & Hammond, 2005 \\
\hline USA $^{g}$ : Texas & $\begin{array}{l}2013 \\
\text { Jun-Aug }\end{array}$ & 270 & Cilantro & Mexico & $\begin{array}{c}\text { Abanyie et al., } \\
2013\end{array}$ \\
\hline $\begin{array}{l}\text { USA }^{\text {g: Iowa, }} \\
\text { Nebraska }\end{array}$ & $\begin{array}{l}2013 \\
\text { Jun-Aug }\end{array}$ & 227 & Lettuce & Mexico & Buss et al., 2016 \\
\hline $\mathrm{USA}^{g}$ & $\begin{array}{c}2014 \\
\text { Jun-Aug }\end{array}$ & 304 & Cilantro & Mexico & CDC, 2014 \\
\hline $\mathrm{USA}^{g}$ & $\begin{array}{c}2015 \\
\text { May-Aug }\end{array}$ & 546 & Cilantro $^{c}$ & UD & CDC, 2015 \\
\hline
\end{tabular}

\footnotetext{
${ }^{\mathrm{a}}$ Both laboratory-confirmed and clinically defined cases are included; ${ }^{\mathrm{b}} 34$ and 232 cases in two consecutive voyages; ${ }^{\mathrm{C}}$ Suspect; ${ }^{\mathrm{d}}$ British Columbia; ${ }^{\mathrm{e}}$ Undetermined; ${ }^{\mathrm{f}}$ Public Health Agency of Canada; ${ }^{\mathrm{g}}$ Multistate outbreak; ${ }^{\mathrm{h}}$ Travelers.
}

\subsubsection{Age and sex distribution}

In endemic areas, most of the studies on prevalence of the infection and association with disease have been conducted in children that have attended clinics, hospitals or laboratories and have been skewed towards those with clinical manifestations. The highest risk of infection and diarrhea occur in the first five years of life (Hoge et al., 1995; Madico et al., 1997; Ortega et al., 1998; ChacínBonilla et al., 2001; Bern et al., 2002). In children less than 18 months of age, Cyclospora infections were detected in Nepal (Sherchand et al., 1999, 2001) but undetected in an outpatient primarycare clinic (Hoge et al., 1995), uncommon in Guatemala (Bern et al., 1999) and Venezuela (Chacín-Bonilla et al., 2001) and present but asymptomatic in Peru (Ortega et al., 1993). It is not known if it is due to weaning maternal antibodies or to limited environmental exposure in this age group.
The community-based studies of Cyclospora age distribution are scarce. In a 2-year cross sectional study in Peru, the prevalence of $C$. cayetanenesis was highest among children 2-4 years of age and was not observed among individuals older than 18 years of age (Madico et al., 1997). In another study from the same region, the infection was not detected in persons older than 11 years of age (Ortega et al., 1998). In Guatemala (Bern et al., 1999), Honduras (Kaminsky, 2002), Haiti (López et al., 2003), Cuba (Nuñez et al., 2003), Venezuela (Chacín-Bonilla et al., 2007), Nepal (Kimura et al., 2005; Tandukar et al., 2013), Turkey (Turgay et al., 2007), and Thailand (Thima et al., 2014) the infection was more frequent in school children less than 15 years of age. In Henan, China, children 7-17 years of age had the highest detection rate (Zhou et al., 2011). The causes for this age distribution pattern are not clear but may be related to predominant modes of exposure. C. cayetanensis is usually transmitted by exposure to contaminated environmental sources from 
which young children are relatively protected (Bern et al., 2002). Significant differences of Cyclospora infection rate by gender have not been reported. In Haiti and Venezuela, the overall male: female risk ratios were 1.04 and 1.3, respectively (Eberhard et al, 1999b; Chacin-Bonilla et al, 2007).

\subsubsection{Seasonal distribution}

In addition to geographic variability, a marked seasonality of the prevalence of Cyclospora infection has been described in several endemic countries. However, it is not uniform among different regions and defies easy explanation (Herwaldt, 2000). The seasonal trend of increased prevalence of cyclosporiasis described in various nations often coincides with warm periods of maximal rainfall as reported in Guatemala (Bern et al., 1999), Honduras (Kaminsky, 2002), Mexico (Orozco-Mosqueda et al, 2014), Jordan (Nimri, 2003), Nepal (Hoge et al., 1993, 1995; Sherchand et al., 2001; Kimura et al., 2005; Bhandari et al., 2015), Indonesia (Fryauff et al., 1999), and China (Zhou et al., 2011).In contrast, infection has been more prevalent in the absence of rain during the drier and hotter months of the year in Lima, Peru (Madico et al., 1997;Bern et al., 2002) and Turkey (Turgay et al., 2007) and in cooler time in Haiti, where temperature fluctuations appear to be the moderator of the infection seasonality (Eberhard et al., 1999b).The seasonal variation of $C$. cayetanensis suggests that environmental factors are important in the life cycle of this parasite and that it is likely to be influenced by several of them such as rainfall, temperature, and humidity.

In non-endemic industrialized nations, individual cases of cyclosporiasis as well as outbreaks are linked mostly to international travel and consumption of contaminated imported produce, usually from endemic regions. The parasite is a common cause of traveler's diarrhea. The first documented US cases occurred in the mid-1980s in travelers returning from Haiti and Mexico (Soave et al., 1986). Between 1997 and 2008, 33.5\% of laboratory confirmed cases of infection in the US were travel related (Hall, 2011), whereas in Canada, 71\% of reported cyclosporiasis cases in 2006 were in travelers (Thomas, 2013). The coccidium was only documented as a significant human pathogen in the mid-1990s when it was recognized as the causative agent of multistate outbreaks of diarrheal illness in the US and Canada, mostly associated with fresh food produce such as soft fruits (berries) and leafy vegetables imported from Mexico and Central America (Chambers et al., 1996; Anonymous, 1997; Herwaldt et al., 1997, 1999, 2000; Dawson, 2005). Since 1990, nearly all reported outbreaks in the US and Canada have been associated with food and almost all the cases have been mostly related to Guatemalan raspberries. These outbreaks occurred during the spring and early summer, a warm and rainy season (Herwaldt, 2000; Shields et al., 2003a). The outbreak that brought cyclosporiasis to importance in North America and established the link to foodborne transmission of infection occurred in the spring of 1996 and was transmitted by fresh raspberries imported from Guatemala. A total of 1,465 cases were reported by 20 states and the District of Columbia in the US, and two Canadian provinces (Herwaldt et al., 1997). In the 1990s, at least 19 outbreaks of cyclosporiasis were documented worldwide, most of them (16) were reported regularly in North America including high-profile, multistate outbreaks in the US and Canada; three were in Nepal (Shlim et al., 1991; Hoge et al., 1993; Rabold et al., 1994; Herwaldt, 2000; Ortega et al., 2010; Kozak et al., 2013). Since 2000, clusters of cases have been documented in the US and Canada; at least 31 epidemics have been reported worldwide, 18 in North America (Table 2). The 2013 multistate outbreaks in the US affected 25 states (primarily Texas, Iowa, and Nebraska) with 631 laboratory confirmed cases of disease. These outbreaks contributed to the largest annual number of reported US cases of cyclosporiasis since 1997 (Abanyie et al., 2013). The 2014 and 2015 multistate epidemics in this country involved 304 and 546 confirmed cases in 19 and 31 states, respectively; most of the cases were reported among Texas residents (CDC, 2014, 2015). The 2015 outbreak in Canada involved Ontario and Quebec provinces (PHAC, 2015). C. cayetanensis outbreaks have been mostly reported in North America, probably due to better detection methods and disease surveillance that have helped in tracking outbreaks. Figures 2 and 3 present the distribution by country and continent, of at least 49 outbreaks reported since 1991, excluding one on a cruise ship that involved people from several countries (Ortega et al., 2010). 

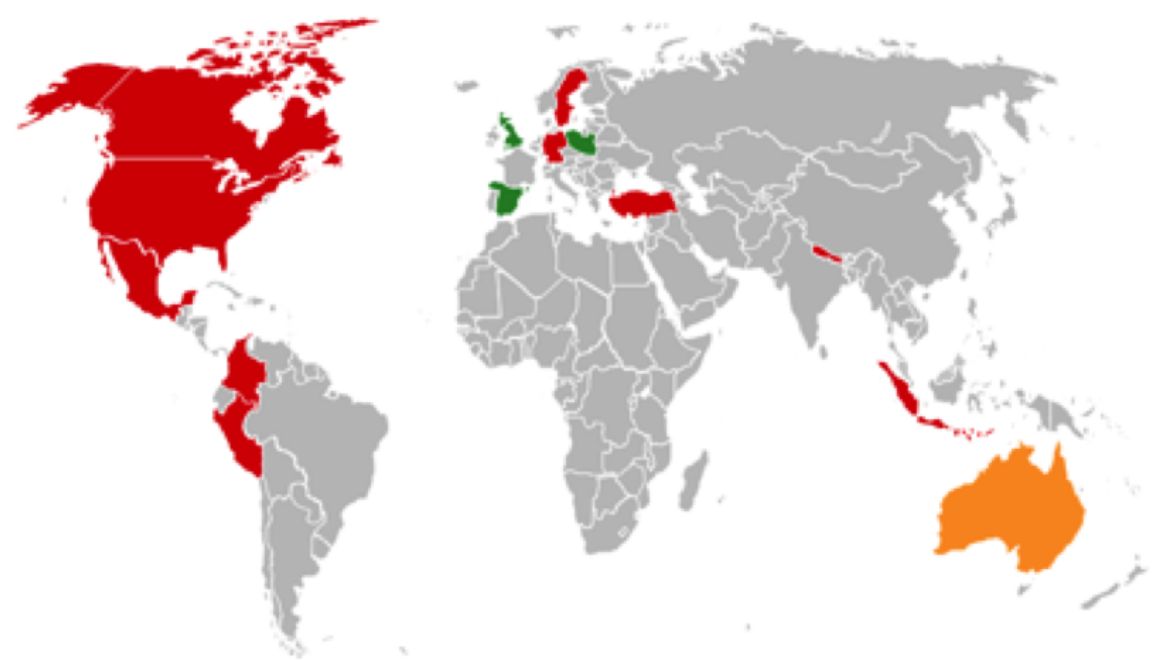

Figure 2. Distribution of worldwide cyclosporiasis outbreaks: countries that have reported epidemics in residents (red), in cruise ship (orange), or in travelers (green)

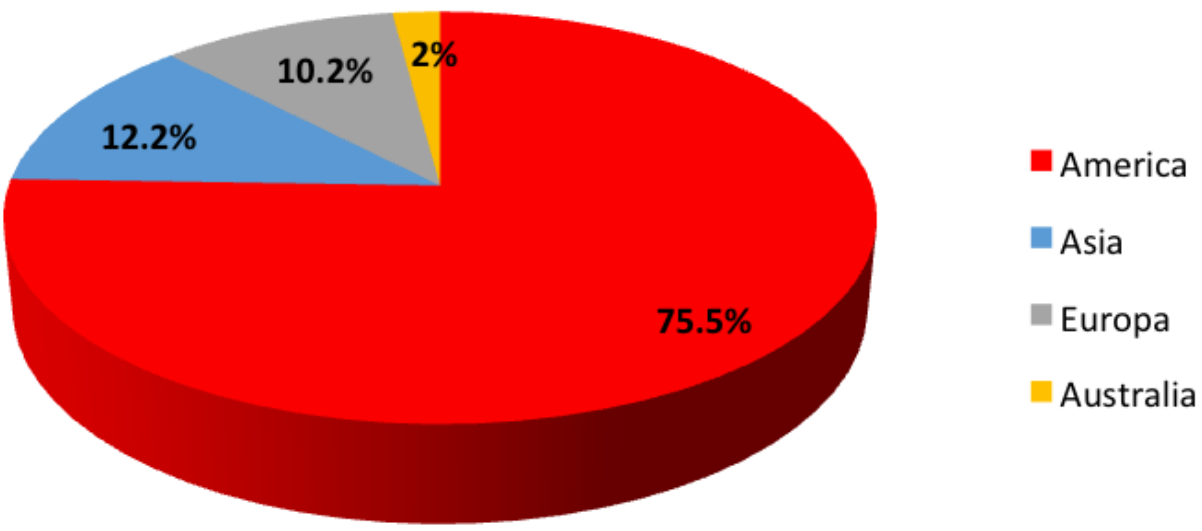

Figure 3. Percentage distribution, by continent, of all reported worldwide cyclosporiasis outbreaks

In North America, outbreaks of waterborne disease have been identified (Huang et al., 1995; Dawson, 2005; Karanis et al., 2007; Baldursson et al., 2011). Exposure to contaminated drinking water, recreational water, or to sewage have spread infection to a lesser extent (Wurtz et al., 1993; Hale et al., 1994; Ooi et al., 1995; Dawson, 2005). Unlike the US and Canada, most cases of cyclosporiasis in
Europe and Australia have been linked with international travel to endemic areas. Cyclosporiasis has been reported in Spain, France, Belgium, Italy, Germany, Greece, United Kingdom, Ireland, Sweden, Switzerland, The Netherlands, New Zealand, and Australia (Shlim et al., 1991; Clarke et al., 1996; Drenaggi et al., 1998; Puente et al., 2006; Bourée et al., 2006, 2007; Ortega et al., 2010). Outbreaks of 
cyclosporiasis have also been reported in travelers from Spain (Puente et al., 2006), Poland (Bednarska et al., 2015) and the United Kingdom (Nichols et al., 2015) (Table 2).

Risk factors for cyclosporiasis in industrialized countries include international travel to cyclosporiasisendemic areas and domestic consumption of contaminated fresh produce imported from these regions. In the US, most of the cases of cyclosporiasis have been linked to imported foods (Herwaldt, 2000). However, there have been sporadic reports of infection where no food source or history of international travel was implicated (Hale et al., 1994; Ooi et al., 1995; Wurtz, 1993). The rate of Cyclospora endemic infection in the general population of North America and United Kingdom was less than 0.5\% between 1992 and 1995 during non-outbreak periods (Herwaldt, 2000; Ribes et al., 2004). Of a total of 370 laboratory-confirmed cases of Cyclospora infection reported during 1997-2009 via the Foodborne Diseases Active Surveillance Network in the USA, $70.3 \%$ of them were concentrated in Georgia and Connecticut. During the period of 2004-2009, 37.8\% (70/185) of the cases were classified as domestically acquired (Hall et al., 2012). In the USA, cyclosporiasis is not thought to be endemic although the possibility of foci with low-level endemicity has been considered (Herwaldt, $2000,2006)$. The sources of a foodborne outbreak in Germany were epidemiologically traced to lettuce and herbs from Germany, France, and Italy; the contamination of food crops could have occurred by seasonal agricultural workers without access to adequate sanitary facilities (Doller et al., 2002). In Europe, C. cayetanensis oocysts were detected in $9 \%$ of samples tested of drinking water, wastewater, and recreational water in Madrid, Spain (Galvan et al., 2013) and in 15.5\% of several environmental matrices including treated wastewater, soil, and vegetables in Apulia, southern Italy with a high prevalence of infection in humans $(27.5 \%, 11 / 40)$ (Giangaspero et al., 2015b). In southern Arizona in the US, $19 \%$ of wastewater samples were positive for the parasite (Kitajima et al., 2014). The German Cyclospora outbreak and the finding of the parasite in different biological matrices in the former countries suggest that irrigation water, soil, and vegetables may represent a source of cyclosporiasis in these areas and illustrates the potential for $C$. cayetanensis to become endemic in industrialized nations. The study on the occurrence of $C$. cayetanensis in treated wastewater from Arizona showed that infection is prevalent in this area. It is conceivable there is some level of waterborne cyclosporiasis in developed nations since several outbreaks of cyclosporiasis have been attributable to water (Rabold et al., 1994; Huang et al., 1995; Aksoy et al., 2007).

\subsubsection{Symptomatology}

Cyclospora cayetanensis is an important emerging cause of diarrhea worldwide that can lead to significant morbidity in children and AIDS patients. It is also a major cause of foodborne diarrheal illness in industrialized countries (Mansfield and Gajadha, 2004). Asymptomatic carriage of Cyclospora occurs. For others, the clinical course and severity of infection can vary considerably from patient to patient, depending in large part on the immune status of the person. The disease is characterized by watery diarrhea, anorexia, fatigue, body aches, mild to severe nausea, abdominal cramping, flatulence, low-grade fever, and weight loss (Herwaldt, 2000). Severe dehydratation can occur (Gajadhar et al., 2015). The infection is usually self-limiting, but symptoms can relapse for several weeks or months. In immunocompetent hosts, mild-to-moderate, selflimiting diarrhea is common. In immunocompromised hosts, severe intestinal injury and prolonged diarrhea is observed (Shields et al., 2003a).

In endemic areas, younger children have more severe symptomatology but frequent exposure may result in a gradual reduction in the severity of illness as they age to asymptomatic infections, and in the absence of symptomatic infections in adults (Madico, 1997; Ortega et al., 1997a; Bern et al., 2002; Chacin-Bonilla, 2010; Thima et al., 2014). In the developed world, travelers and expatriates infections are almost always symptomatic.

Infection causes significant morbidity in immunocompromised individuals, in particular those with HIV infection. The risk of infection and severity of illness are related to the state of immunosuppression of the patients. They tend to present severe, chronic or intermittent diarrhea that may last for weeks with significant weight loss. The average duration of diarrhea for HIV patients is longer than that for HIV negative patients (199 days vs 57.2 days) (Sifuentes-Osorio et al., 1995). There is a high recurrence rate of cyclosporiasis in HIV patients (Pape et al., 1994, Soave, 1996). Acalculous cholecystitis has been reported in these patients (SifuentesOsorio et al., 1995; Zar et al., 2001).

Cyclosporiasis has been associated with various sequelae including biliary disease (Sifuentes-Osorio et al., 1995; de Gorgolas et al., 2001), acalculous cholecystitis (Sifuentes-Osorio et al., 1995; Zar et al., 2001), GuillainBarre syndrome (Richardson et al., 1998), and Reiter syndrome (Connor et al., 2001).

Histopathological alterations of the small intestine include diffuse edema and infiltration by inflammatory cells with villous atrophy and crypt hyperplasia, characterized by shortened blunted villi and increased crypt length (Ortega, 1997a). Loss of villar surface in the intestine can occur (Gajadhar et al., 2015). An accumulation of an electrondense phospholipid membrane/myelin-like material of the enterocytes has been decribed (Connor et al., 1999).

\subsubsection{Economic impact}

Cyclosporiasis has serious implications for young children, travelers to endemic areas, immunocompromised patients, and naive populations. Although the global incidence and prevalence of morbidity, disability, and mortality associated with acute and chronic cyclosporiasis have not been estimated, diarrheal disease disproportionately affects developing countries, but gastroenteritis also is a significant problem in industrialized nations. 
About $99 \%$ of the USA cyclosporiasis cases are estimated to be foodborne (Mead et al., 1999), resulting in an estimated 11,407 foodborne incident cases and 11 hospitalizations per year (Scallan et al., 2011). From these estimates, the annual cost of infection in the US has been estimated to be $\$ 11$ million using a basic Cost of Illness (COI) model and \$17 million when pain and suffering were also considered in the COI model (Scharff, 2012). In 1996 and 1997, the US and Canadian health officials reported 2,944 cases (132 clusters) of cyclosporiasis (Shields et al., 2003a).

A study was conducted to estimate the disease burden of 14 pathogens in food sources in the US, using attribution data from outbreak investigation and expert elicitation, from 1999 through 2008. The health burden associated with each pathogen was measured using new estimates of the cost of illness and loss of quality- adjusted life year (QALY) from acute and chronic illness and mortality. For Cyclospora, annual number of illnesses, hospitalizations, and QALY losses were 11,407 (137-37,673), 11 (0-109), and 10 (0-33), respectively. Annual burden of disease was $\$ 2$ million and ranged from $\$ 0$ to $\$ 8$. Based on exposure to this pathogen, produce was responsible for $96 \%$ of illness burden (Batz et al., 2012).

Sporadic outbreaks of cyclosporiasis, including the multistate outbreaks in the USA in 2013-2015 (Abanyie et al, 2013; CDC, 2014, 2015) and Canada in 2015 (PHAC, 2015), underscore the continued burden of illness this protist presents in developed countries. Cyclosporiasis might have long-term negative consequences since early childhood diarrheal illness could have serious impacts on children's growth and cognitive development and may predispose them to chronic metabolic disease in later life (Guerrant et al., 2013).

\subsection{Taxonomic Classification of the Agent}

\subsubsection{Physical description of the agent}

The environmental stage excreted in the feces is the oocyst. Oocysts are microscopic with a diameter of 7.7-9.9 $\mu \mathrm{m}$, and spheroidal in shape. With the modified acid-fast stain, some stain dark red and have a variable number of dark inclusion bodies, whereas others do not stain at all and appear as transparent spheres. Viewed with epifluorescence ultraviolet microscopy using a $365 \mathrm{~nm}$ or a $490 \mathrm{~nm}$ dichromatic filter, oocysts autofluoresce blue or green (Ortega et al., 1993). Viewed with transmission electron microscopy, a freshly excreted oocyst contains a granular undifferentiated cytoplasm surrounded by a twolayered oocyst wall (63 and $50 \mathrm{~nm}$ thick, respectively); the cytoplasm has no unique distinguishing structures. Upon exposure to air the oocyst undergoes sporulation. This process takes 7-15 days The oocysts are not infectious upon excretion. About $40 \%$ of oocysts sporulate and become infectious within 14 days. at temperatures between 23 and $32^{\circ} \mathrm{C}$ (Ortega et al., 1994). A sporulated oocyst contains two sporocysts, each with 62-nm-thick walls surrounding a plasma membrane. Each sporocyst has a Stieda and substiedal bodies at one end and a residuum consisting of spherical globules. Each sporocyst has two sporozoites. The presence of two sporozoites in each of the two sporocysts is the defining diagnostic criterion for the genus Cyclospora (Ortega et al., 1993, 1994).

\subsubsection{Taxonomy}

Members of the genus Cyclospora are protozoan parasites in the subphylum Apicomplexa, subclass Coccidiasina, order Eucoccidiorida, family Eimeriidae (Shields et al., 2003a). Nineteen species of Cyclospora have been described, based mainly on conventional microscopic analysis of oocsts in feces from reptiles (mostly snakes), insectivores, rodents, primates, and humans (Lainson, 2005). Cyclospora cayetanensis is the only species in the genus known to infect humans. Cyclospora colobi, $C$. papionis, and $C$. cercopitheci were identified on the basis of $18 \mathrm{~S}$ rRNA gene sequence analysis from primates in Ethiopia and Kenya. These three species are host specific although they are closely related to $C$. cayetanensis based on morphologic and molecular studies (Eberhard et al., 1999a). C. colobi-like organisms were identified in snubnosed golden colobus monkeys in northwestern China (Zhao et al., 2013). Three additional species have been reported to infect dairy cattle in China (Li et al., 2007), drills on Bioko Island, western Africa (Eberhard et al., 2014) and rhesus monkeys; the latter was named Cyclospora macacae (Li et al., 2015).

Beginning in 1979, before C. cayetanensis was identified and named, there were reports describing an Isospora-like organism, a coccidian-like body, large Cryptosporidium, or Cyanobacterium-like body, associated with diarrhea in humans (Ashford, 1979; Long et al., 1991; Shlim et al., 1991; Gascon et al., 1993). Subsequently, following successful sporulation and excystation of the oocysts isolated from Peruvians with persistent diarrhea, $C$. cayetanensis was described and named (Ortega et al., 1993, 1994). Molecular analysis of nuclear ssrDNA sequences suggested that $C$. cayetanensis is phylogenetically closely related to other coccidia, especially members of the genus Eimeria(Relman et al., 1996; Ogedengbe et al., 2015; Cinar et al., 2015). Phylogenetic analysis grouped the Cyclospora species infecting primates, including $C$. cayetanensis in humans, forming a group closely related to avian Eimeriaspecies (Li et al., 2015). Because of limited molecular testing of specimens from humans it is not yet known whether all human Cyclospora isolates belong to the same species and whether the closely related Cyclospora species described from lower primates infect humans.

Different genes have been assessed for elucidating evolutionary relationships between $C$. cayetanensis strains to aid in molecular epidemiology. Analysis of heat shock protein and 18 ribosomal RNA (18S rRNA) genes of $C$. cayetanensis from humans in Mexico, Peru, and Nepal showed existence of genetically homogeneous population for the $C$. cayetanensis parasites at both genes (Sulaiman et al., 2013, 2014). Analysis of the 18S rRNA gene of $C$. cayetanensis isolates and among members of $C$. colobi, $C$. papionis, and $C$. cercophiteci showed a significant distinct 
genetic variation among species and a minor genetic diversity within the species (Sulaiman et al., 2014). Examination of 18S rRNA gene sequences of isolates from China also revealed only minor sequence polymorphisms (Zhou et al., 2011). The intervening transcribed spacer 1 (ITS-1) is highly variable even within individual oocysts and is therefore not reliable for inferring relationships between strains (Olivier et al., 2001). Efforts are underway to characterize a few more genetic loci to better understand the population genetic structure and transmission dynamics of Cyclospora.

Recently, the full-length mitochondrial and apicoplast genomes of $C$. cayetanensis have been reported (Tang et al., 2015; Qvarnstrom et al., 2015; Cinar et al., 2015). Both genomes are highly similar to those of cecum-infecting avian Eimeria spp. Sequence variations in the mitochondrial genome between two Chinese isolates and one US $C$. cayetanensis isolate have been identified (Tang et al., 2015). Another study found the mitochondrial genome to have a close phylogenetic relationship with Eimeria magna,a coccidian infecting rabbits (Cinar et al., 2015). Through a greater availability of whole genome sequencing and comparative genomic analysis, it was shown that sequences would improve our understanding of the biology of $C$. cayetanensis which probably possesses a classical coccidian metabolism and has a host cell invasion system very similar to Eimeriaspp. andToxoplasma gondii. The dominant surface antigens observed in other coccidian are not present or significantly diminished (Liu et al., 2016). Nevertheless, these results need to be validated. Further characterization of the genomes of additional $C$. cayetanensis isolates and other Cyclospora species is needed to improve our comprehension of the taxonomic position and biology of Cyclospora.

\subsubsection{Life cycle}

Humans are the only known host for $C$. cayetanensis. It is an obligate intracellular parasite that requires a single host to complete the entire life cycle. Asexual and sexual stages have been observed within the epithelium of the gastrointestinal tract of the host (Sun et al., 1996; Ortega et al., 1997a; Connor et al., 1999).

The life cycle (Figure 4) starts with the ingestion of the sporulated oocyst, which excysts in the gut releasing infective sporozoites that invade the epithelial cells of the duodenum and jejunum (Sun et al., 1996; Ortega et al., 1997a). The sporozoites transform into trophozoites which undergo merogony and form two types of meronts. Type I meronts contain 8-12 merozoites which penetrate host cells and each merozoite develops into a type II meront that develops to contain four merozoites. Once liberated, these merozoites enter other host cells and begin the gametogony cycle by differentiating into either male (microgametocyte) or female (macrogametocyte) stages. The male stage forms flagellated microgametes. The fertilized macrogametocyte develops into a zygote. A resistant wall is then formed around it and develops into an oocyst which contains the sporont (Ortega et al., 1997a; Connor et al., 1999). The unsporulated, noninfective oocysts are passed in the stool and sporulation occurs yielding infective oocysts containing two sporocysts, each one with two banana-shaped sporozoites (Ortega et al., 1993, 1994). The environmental conditions for sporulation are not yet completely understood although for other genera of coccidia, exposure to air is required, Most coccidians pathogenic to humans require short periods of time to sporulate. However, Cyclospora oocysts require prolonged time outside the host, depending on climatic factors, for sporulation to take place in the environment (Ortega et al., 1998). Experimentally, sporulation has been carried out by suspending oocysts in $2.5 \%$ potassium dichromate in water often with constant or intermittent stirring (Ortega et al., 1993). About $40 \%$ of oocysts sporulate within 14 days at temperatures between 23 and $32^{\circ} \mathrm{C}$ (Ortega et al., 1994). It is not known why $C$. cayetanensis requires a much longer time to sporulate than other coccidia. 


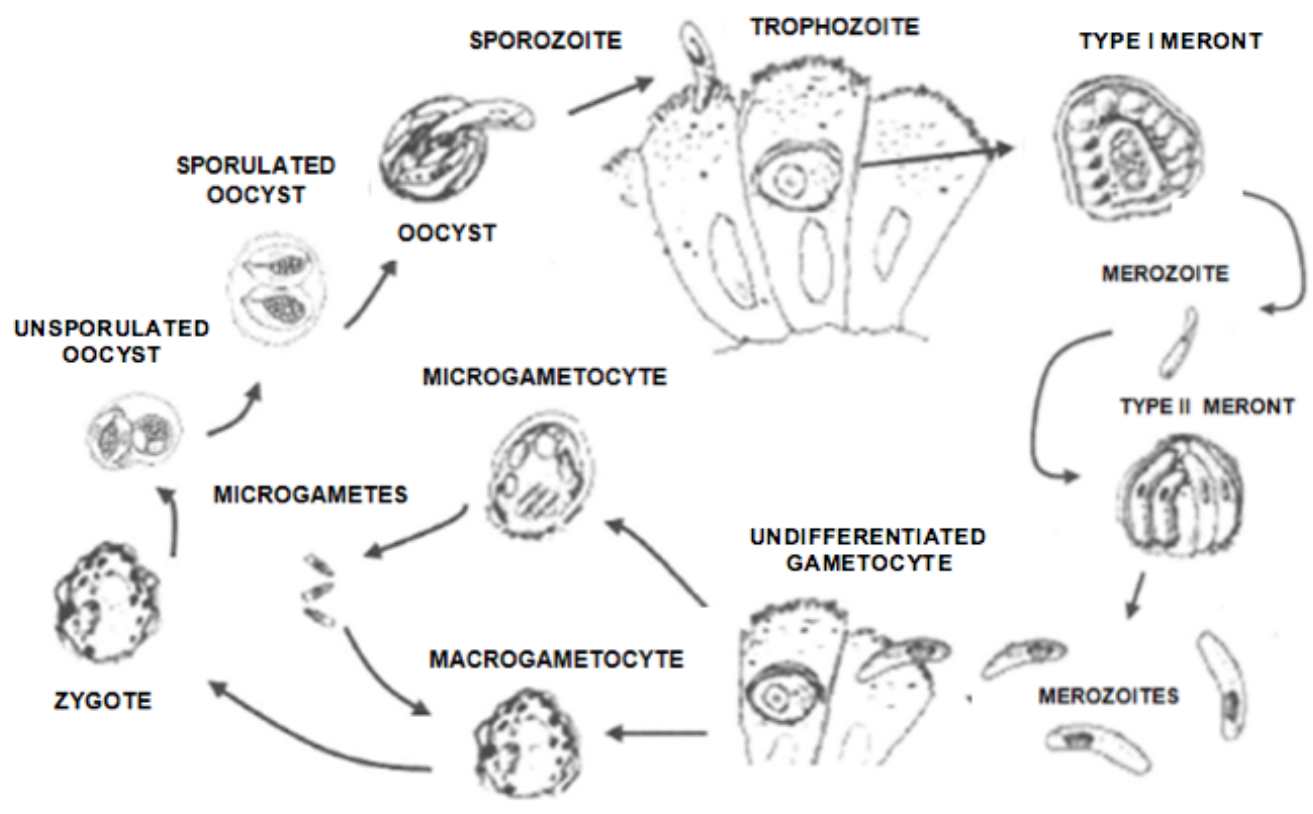

Figure 4. Diagrammatic representation of life cycle of Cyclospora cayetanensis

\subsection{Transmission}

Transmission entails ingestion of sporulated (infectious) oocysts in contaminated food, water, or soil by a susceptible human host. This is after some time period after fecal excretion which allows for the oocysts to sporulate and become infectious. The triggers and conditions necessary for Cyclospora oocysts to become infectious in the environment are not fully understood. The need for a trigger to initiate infection is suggested by the unsuccessful attempts to experimentally infect humans (Alfano-Sobsey et al., 2004).

In developed nations, risk factors and modes of transmission have been identified. Most cases have been related to international travel or to foodborne outbreaks caused by imported produce from endemic regions (Herwaldt et al., 1997, 1999, 2000; Gascon et al., 2001; Mansfield and Gajadha, 2004; Dawson, 2005; Puente et al., 2006; Bourée et al., 2006, 2007). In contrast, the risk factors and routes of spread for $C$. cayetanensis in developing areas remain poorly understood. Variables related to water, eating fresh food, contact with soil, agricultural occupations, lack of hand washing, and factors associated with low socioeconomic status have been linked to infection (Wang et al., 2002; Chacin-Bonilla et al., 2007, 2008a; Zhou et al., 2011; Tandukar et al., 2013). The biologic and epidemiologic features of $C$. cayetanensis that facilitate transmission might involve an interplay among different routes of spread but the relative contributions of the different modes of transmission to the overall burden of cyclosporiasis are hard to quantify. In developing countries, few studies have been conducted to address the modes of spread of infection. However, multiple routes of transmission almost certainly exist in these areas.

\subsubsection{Foodborne transmission}

Cyclosporiasis has been associated with eating raw vegetables in Nepal (Sherchand et al., 1999, 2001) and Jordan (Nimri, 2003) and consumption of fresh produce without proper washing in Nepal (Bhandari et al., 2015). In endemic areas, strawberries, buffalo milk, and marinated fish were identified as risk factors in five cases of traveler's diarrhea (Gascon et al., 2001).

Cyclospora cayetanensis has been responsible for numerous high-profile outbreaks of foodborne disease from contaminated Guatemalan raspberries in the US and Canada (Herwaldt et al., 1997, 1999, 2000; Ho et al., 2002; Shields et al., 2003a; Dawson, 2005). Additional outbreaks of cyclosporiasis in both countries, and Europe were associated with consumption of basil, lettuce, field greens and snow peas (Herwald et al., 1997; Ho et al., 2002; Doller et al., 2002; Hoang et al., 2005; Insulander et al., 2010; Kozak et al., 2013; Gibbs et al., 2013; Abanyie et al., 2015; CDC, 2014, 2015; Buss et al., 2016) (Table 2). In the US, outbreaks occurred in 25 states in the summer of 2013, with most cases in Texas, Iowa, and Nebraska (Abanyie et al., 2013). In June-July 2014 and May-September 2015, epidemics affected 19 and 31 states, respectively; most of the cases were reported from Texas (CDC, 2014, 2015). Quebec and Ontario experienced outbreaks from May to August of 2015 (PHAC, 2015) (Table 2). Several outbreaks have been traced to fresh foods that are difficult to clean thoroughly and are consumed without processing that can inactivate or remove the oocysts, such as fresh berries and leafy greens. Pasteurized foods or thoroughly heated before consumption have not been associated with illness (Dawson, 2005). Foodborne cyclosporiasis has shown to be a great concern in food production and a significant problem for public health worldwide. 


\subsubsection{Waterborne transmission}

In countries where $C$. cayetanensis is endemic and water and sewage treatment systems insufficient or lacking, waterborne oocysts are a likely source of infection because they are environmentally robust (Mansfield and Gajadha, 2004), sufficiently small to penetrate the physical barriers of water treatment, and insensitive to many disinfectants used in the water industry (Rabold et al., 1994; Soave et al., 1998). Furthermore, the infectious dose is low, although it has not been fully described (Sterling et al, 1999; Dixon et al, 2005), probably between 10 and 100 oocysts (Adam et al., 1999).

In Nepal, infection was associated with untreated water in several studies (Hoge et al., 1993; Tandukar et al., 2013; Bhandari et al., 2015) and three other outbreaks were related to drinking water (Shlim et al., 1991; Hoge et al., 1993; Rabold et al., 1994). An outbreak affecting foreign soldiers and dependents was linked with drinking water containing Cyclospora oocysts. This water was a mixture of river and municipal water that was chlorinated and filtered but the organisms were not completely removed (Rabold et al., 1994).

The first reported outbreak of cyclosporiasis in the US was in Chicago, where 23 cases were linked to a hospital water supply. Epidemiologic studies implicated tap water in the physician's dormitory as the most likely source of the outbreak. Stagnant water in a storage tank may have contaminated the water supply after a pump failure. Examination of water samples did not reveal Cyclospora oocysts (Huang et al., 1995). A follow-up study of this epidemic revealed that drinking tap water and attendance at a house staff party were significant risk factors. For this reason, the possibility of a food-borne outbreak associated with the food served at the house staff party has been pointed out (Ortega et al., 2010).

In Peru, cyclosporiasis was associated with consumption of unchlorinated water (Zerpa et al., 1995). In a case-control study from Guatemala, several variables related to water were associated with risk for Cyclospora infection including drinking untreated water, and swimming in rivers or springs (Bern et al., 1999). In Haiti, the only factor associated with infection was drinking water from an artesian well (López et al., 2003).In another study in Turkey, a cyclosporiasis outbreak was linked to drinking water (Aksoy et al., 2007).

Sewage water was also identified as a possible source of cyclosporiasis in Nepal (Sherchand et al., 1999, 2001). In an Egyptian village, Cyclospora oocysts, possibly from sewage contamination, were detected in several water sources suggesting water was an important source of infection (el-Karamany et al., 2005). Of 524 waterassociated outbreaks of protozoan disease reported worldwide, $C$. cayetanensis was the causative agent in nine (1.7\%) (Karanis et al., 2007; Baldursson et al., 2011).

It has been demonstrated that shellfish Identification of C. cayetanensis in shellfish in Alexandria, Egypt (Negm, 2003) and Izmir, Turkey (Aksoy et al., 2014) suggests that freshwater run-off from land can carry oocysts into the marine ecosystem, a further concern for waterborne oocysts in the spread of infection where seafood consumed raw and recreation in marine water could potentially increase the risk of infection.

These findings of $C$. cayetanensis in several types of water (Table 3) suggest the potential spread of the parasite by drinking and recreational water, including chlorinated water, and wastewater in endemic areas and potentially in non-endemic areas as a single event. It has been hypothesized that contamination of Guatemalan raspberries could have occurred during the preparation of insecticides and fungicides using contaminated river water or by crosscontamination from hands of pickers or handlers of crops (Sterling et al., 1999; Sathyanarayanan et al. 2004). However, even when $C$. cayetanensis has been detected in water and food related to an outbreak, the source of contamination has not been established (Huang et al., 1995; Colley, 1996; Herwaldt et al., 1997). It remains a matter of speculation. $C$. cayetanensis can contaminate crops via different pathways including black water used for irrigation or spraying of crops, contact with contaminated soil, or contact with infected food handlers with hands that have been in contact with contaminated soil (Dawson, 2005).

Table 3. Isolation and prevalence of Cyclospora in environmental matrices from several countries

\begin{tabular}{|c|c|c|c|}
\hline Area & Matrices Analyzed & $\begin{array}{c}\text { Contaminated Percentage } \\
\text { (\# of Samples) }\end{array}$ & Reference \\
\hline Cambodia & Water spinach & $\begin{array}{c}8.3 \% \\
(3 / 36)\end{array}$ & $\begin{array}{l}\text { Vuong et al., } \\
2007\end{array}$ \\
\hline Canada & $\begin{array}{c}\text { Pre-cut salads, leafy } \\
\text { greens }\end{array}$ & $\begin{array}{c}1.6 \% \\
(9 / 544)\end{array}$ & $\begin{array}{l}\text { Dixon et al., } \\
2013\end{array}$ \\
\hline Costa Rica & Lettuce & $\begin{array}{c}4 \% \\
(2 / 50)\end{array}$ & $\begin{array}{l}\text { Calvo et al., } \\
\quad 2004\end{array}$ \\
\hline Egypt & $\begin{array}{l}\text { Drinking water and } \\
\text { rivers }\end{array}$ & $\begin{array}{c}0.2 \% \\
(2 / 840)\end{array}$ & $\begin{array}{l}\text { el-Karamany } \\
\text { et al., } 2005\end{array}$ \\
\hline Egypt & Potable water & $\begin{array}{c}21.3 \% \\
(64 / 300)\end{array}$ & $\begin{array}{c}\text { Elshazly et al., } \\
2007\end{array}$ \\
\hline
\end{tabular}




\begin{tabular}{|c|c|c|c|}
\hline Area & Matrices Analyzed & $\begin{array}{c}\text { Contaminated Percentage } \\
\text { (\# of Samples) }\end{array}$ & Reference \\
\hline Ghana & $\begin{array}{l}\text { Sachet drinking } \\
\text { water }\end{array}$ & $\begin{array}{c}59.3 \% \\
(16 / 27)\end{array}$ & $\begin{array}{c}\text { Kwakye-Nuako } \\
\text { et al., } 2007\end{array}$ \\
\hline Ghana & Vegetables & $\begin{array}{c}11.9 \% \\
(20 / 168)\end{array}$ & $\begin{array}{l}\text { Duedu et al., } \\
2014\end{array}$ \\
\hline Guatemala & Rivers & $\begin{array}{c}6.7 \% \\
(2 / 30)\end{array}$ & $\begin{array}{l}\text { Bern et al., } \\
1999\end{array}$ \\
\hline Guatemala & $\begin{array}{l}\text { Drinking water } \\
\text { sources }\end{array}$ & $\begin{array}{l}41.7 \% \\
(5 / 12)^{\mathrm{a}}\end{array}$ & $\begin{array}{l}\text { Dowd et al., } \\
2003\end{array}$ \\
\hline Italy & Tap water & $\begin{array}{c}30 \% \\
(3 / 10)^{\mathrm{a}}\end{array}$ & $\begin{array}{l}\text { Giangaspero } \\
\text { et al., 2015a }\end{array}$ \\
\hline Italy & $\begin{array}{l}\text { Vegetables and } \\
\text { fruits }\end{array}$ & $\begin{array}{l}12.2 \% \\
(6 / 49)^{\mathrm{a}}\end{array}$ & $\begin{array}{l}\text { Giangaspero } \\
\text { et al., } 2015 b\end{array}$ \\
\hline Italy & Treated wastewater & $\begin{array}{l}21.3 \% \\
(20 / 94)^{\mathrm{a}}\end{array}$ & $\begin{array}{l}\text { Giangaspero } \\
\text { et al., } 2015 b\end{array}$ \\
\hline Italy & Well water & $\begin{array}{c}6.2 \% \\
(1 / 16)^{\mathrm{a}}\end{array}$ & $\begin{array}{l}\text { Giangaspero } \\
\text { et al., } 2015 b\end{array}$ \\
\hline Italy & Soil & $\begin{array}{l}11.8 \% \\
(6 / 51)^{\mathrm{a}}\end{array}$ & $\begin{array}{l}\text { Giangaspero } \\
\text { et al., } 2015 b\end{array}$ \\
\hline Peru & Vegetables & $\begin{array}{c}1.7 \% \\
(3 / 172)\end{array}$ & $\begin{array}{l}\text { Ortega et al., } \\
1997 \mathrm{~b}\end{array}$ \\
\hline Peru & Wastewater & $\begin{array}{l}72.7 \% \\
(8 / 11)\end{array}$ & $\begin{array}{l}\text { Sturbaum et } \\
\text { al., } 1998\end{array}$ \\
\hline Spain & $\begin{array}{l}\mathrm{DWTP}^{\mathrm{b}}, \mathrm{WWTP}^{\mathrm{c}}, \\
\text { rivers }\end{array}$ & $\begin{array}{c}9 \% \\
(20 / 223)\end{array}$ & $\begin{array}{l}\text { Galván et al., } \\
2013\end{array}$ \\
\hline Turkey & Shellfish & $\begin{array}{c}26.4 \% \\
(14 / 53)^{\mathrm{a}}\end{array}$ & $\begin{array}{c}\text { Aksoy et al., } \\
2014\end{array}$ \\
\hline Tunisia & Wastewater & $\begin{array}{c}0.4 \% \\
(1 / 232)^{\mathrm{a}}\end{array}$ & $\begin{array}{l}\text { Ben-Ayed et } \\
\text { al., } 2012\end{array}$ \\
\hline USA & WWTP influent & $\begin{array}{c}25 \% \\
(6 / 24)^{\mathrm{a}}\end{array}$ & $\begin{array}{c}\text { Kitajima et al., } \\
2014\end{array}$ \\
\hline USA & WWTP effluent & $\begin{array}{l}12.5 \% \\
(3 / 24)^{\mathrm{a}}\end{array}$ & $\begin{array}{c}\text { Kitajima et al., } \\
2014\end{array}$ \\
\hline Venezuela & Lettuce & $\begin{array}{c}5.9 \% \\
(6 / 102)\end{array}$ & $\begin{array}{c}\text { Devera et al., } \\
2006\end{array}$ \\
\hline Vietnam & Lakes and rivers & $\begin{array}{c}63.6 \% \\
(84 / 132)^{\mathrm{a}}\end{array}$ & $\begin{array}{l}\text { Miegeville et } \\
\text { al., } 2003\end{array}$ \\
\hline Vietnam & Herbs and water & $\begin{array}{c}10.1 \% \\
(58 / 575)\end{array}$ & $\begin{array}{c}\text { Tram et al., } \\
2008\end{array}$ \\
\hline
\end{tabular}

\subsubsection{Soil transmission}

In developing countries, contact with soil is considered a risk factor for cyclosporiasis (Chacin-Bonilla, 2008a). Studies from Peru (Madico et al., 1997), Guatemala (Bern et al., 1999), Venezuela (Chacin-Bonilla et al., 2007), and Egypt (el-Karamany et al., 2005) found soil to be a potential source of infection. In a study from Nepal, the $C$. cayetanensis was more prevalent where agriculture work and lack of hand washing were risk factors for infection (Tandukar et al., 2013). Several studies indicated that a variety of parasites were present in leafy vegetables probably resulting from exposure of the edible parts to the soil surface (Uga et al., 2009).

Also in developed regions, contact with soil appears to play a role in the spread of infection. In an outbreak of cyclosporiasis in Florida, US, soil was a risk factor for infection (Koumans et al., 1998). In Germany, an outbreak was associated with lettuce from farms in Germany, France, and Italy; contamination of food crops could have occurred by seasonal agricultural workers from endemic areas without access to adequate sanitary facilities (Doller et al., 2002).

Variables associated with low socioeconomic status 
could predispose persons to infection. In Venezuela, the majority of cases of cyclosporiasis were clustered in the areas of extreme poverty where living in a hut, not having a toilet, and having contact with fecal-contaminated soil were strongly associated with infection (Chacin-Bonilla et al., 2007). The main finding of this study was the strong correlation of stool positivity for Cyclospora with environments conducive to human fecal contamination, which suggests that anthroponotic transmission is possible through contact with contaminated soil in this area. Indeed, this factor was strongly linked to infection. The findings indicated an inverse relationship between socioeconomic status and infection and showed that cyclosporiasis, as well as other communicable infections, affects families living in substandard housing developments. In Haiti and China, higher rates of infection have been noted in areas, where deficient sanitary facilities and personal hygiene and soil frequently contaminated with feces were present (Lopez et al., 2003; Wang et al., 2002; Zhou et al., 2011).

The reasons for a higher prevalence of infection in older children (Chacín-Bonilla, 2010; Zhou et al., 2011; Tandukar et al., 2013; Thima et al., 2014) could be explained by other exposure and behavioral sub-factors strongly correlated with low socioeconomic status rather than age alone. Contamination of soils by inadequate defecation practices might be significant determinants for infection. Since outdoor defecation is frequent, non-supervised children may be more exposed to infection.

These results highlight the potential links between social marginalization and Cyclospora infection. Individuals of all socioeconomic strata can acquire cyclosporiasis. However, social inequality could mediate patterns of human exposure and infection. Impaired social environments could also influence patterns of human exposure, as persons within these areas may lack resources necessary for proper sanitation or educational avoidance of transmission routes. Living in physically impaired environments, where access to clean water and food is limited or where contact with soil is frequent, can increase exposure to Cyclospora oocysts. The effects of family wealth on cryptosporidiosis risk have also been demonstrated in several countries including the US (Chacin-Bonilla et al., 2008b; Becker et al., 2015).

Infections linked to contact with soil provide reasons to believe that this route of spread could be a mayor source of infection in areas of poor environmental sanitation, and poverty a predisposing factor. Large studies in endemic countries are required to elucidate soil transmission in vulnerable populations.

\subsubsection{Reservoirs: The role of animals in transmission}

Humans are the only known hosts of $C$. cayetanensis. However, the mechanical spread of the parasite through domestic animals was suggested in early studies in developing regions. Contact with animals is considered a risk factor for infection in Guatemala (Bern et al., 1999), Peru (Bern et al., 2002), Jordan (Nimri, 2003), Nepal (Sherchand et al., 1999, 2001; Bhandari et al., 2015) and Egypt (el-Karamany et al., 2005). Oocystsresembling those of $C$. cayetanensis have been identified, using conventional methods, in the feces of several animals including ducks (Zerpa et al., 1995), chickens (García-López et al., 1996; Sherchand et al., 1999, 2001), mice and rats (Sherchand et al., 2001), dogs (Yai et al., 1997; Sherchand et al., 2001), and birds (Perez Cordon et al., 2009). Cyclospora-like oocysts were observed in feces of animals (carnivores, artiodactyla, and nonhuman primates) from a Spanish zoological garden (Perez Cordon et al., 2008). The presence of $C$. cayetanensis has also been demonstrated by PCR in feces of one chicken, two dogs and one monkey (Chu et al., 2004) and in one rhesus monkey (Li et al., 2015). No histological evidence of Cyclospora infecting tissues were presented in the prior studies. In contrast to these findings, the parasite was not detected in Haiti from 327 domestic animals, including pigeons, chickens, ducks, turkeys, guinea pigs, cats, dogs, goats, pigs, horses, and cattle (Eberhard et al., 1999c) and in Brazil from 140 stray dogs (Carollo et al., 2001), and Lima, Peru (Ortega et al., 1997b). Attempts toinfect several animals with $\mathrm{C}$. cayetanensis have been unsuccessful, suggesting host specificity (Eberhard et al., 2000). Although C. cayetanensis was reported to be propagated in albino mice (Sadaka et al., 2001) and guinea pigs (Wang et al., 2002) the findings could not be confirmed (Ortega et al., 2010). The parasite has been detected in shellfish (Negm, 2003; Aksoy et al., 2014). Free living nematodes, insects, and rotifers could play a role in the spread of Cyclospora (Ortega et al., 2010).

\subsubsection{Incubation period}

The median incubation period in most foodborne outbreaks has been 7 days (Herwaldt et al., 1997, 1999; Koumans et al., 1998; CDC, 1998). Among symptomatic individuals in outbreaks, the incubation period averages one week and ranges from approximately 2 to 14 days (Herwaldt, 2000, 2006). In a Cyclospora outbreak from Peru in 2004, analysis of the epidemiological curve suggested an incubation period of 2 to 6 days (TorresSlimming et al., 2006).

\subsubsection{Period of communicability}

\subsubsection{Shedding levels}

Cyclospora oocysts typically are shed in relatively low numbers, even by non- immune ill persons (Herwaldt, 2000). Oocysts are not shed during the first week of infection, but in heavy infections, numerous oocysts are passed with loose feces (Gajadhar et al., 2015). In fecal material the number of Cyclospora oocysts may range from $10^{2}$ to $10^{4}$ oocysts per gram of stool (Shields et al, 2003a).

\subsubsection{Time of shedding}

Dissapearance of symptoms and shedding of oocysts usually occur within a few days to 1 or 2 weeks (Soave et al., 1986; Shlim et al., 1991; Hoge et al., 1993). However, intermittent shedding of Cyclospora oocysts can continue even when the host is asymptomatic. Some untreated patients excrete oocysts after symptoms resolve (Shlim et al., 1991; Huang et al., 1995; Gajadhar et al., 2015) or have 
symptoms longer than oocysts excretion (Hoge et al., 1993; Gajadhar et al. 2015) for several weeks. Untreated young children shed Cyclospora for a mean of 22-23 days (Ortega et al., 1993).

\subsubsection{Population susceptibility}

The susceptible populations to symptomatic illness include the very young, the elderly, immune-compromised persons, and those without previous exposure. In endemic and non-endemic areas, the models of susceptibility are different.

In developing countries, risk categories for cyclosporiasis include children, foreigners, and immunocompromised patients. Young children, in the first five years of age, are more likely to develop clinical symptoms (Hoge et al., 1995; Madico et al., 1997; Ortega et al., 1998; Sherchand et al. 1999, 2001; Chacín-Bonilla et al., 2001; Bern et al., 2002). Among resident foreigners and expatriates, the disease is common (Clarke and McIntyre, 1996; Drenaggi et al., 1998; Shields et al., 2003a; Puente et al., 2006; Bourée et al., 2006, 2007) and outbreaks have been reported (Shlim et al., 1991; Hoge et al., 1993; Rabold et al., 1994; Blans et al., 2005; Puente et al., 2006; Bednarska et al., 2015; Nichols, 2015) (Table 2). Among HIV-infected patients, Cyclospora is an important cause of diarrhea (Chacin-Bonilla, 2010).

In the developed world, cyclosporiasis is observed in the general population regardless of age including immunocompetent individuals, HIV-infected individuals, and immunocompromised patients (Kurniawan et al., 2009; Gajadhar et al., 2015).

\subsection{Population and Individual Control Measures}

\subsubsection{Vaccines and drug therapy}

No vaccine is available for cyclosporiasis.

Trimethoprim-sulfamethoxazole (TMP-SMX) was first used to treat cyclosporiasis in 1993 (Madico et al., 1993) and since 1995, it has been the drug combination of choice for managing infection (Hoge et al., 1995). It can be treated with the drug at $160-800 \mathrm{mg}$ twice a day for 7 days or the same dose 4 times a day for 10 days in immunocompromised patients with AIDS, often with resolution of symptoms and oocysts shedding in 1-2 days (Madico et al., 1993; Hoge et al., 1995). In Peru, children with Cyclospora infection received a 3-day course of TMPSMX at 5-25 mg/kg of body weight and stopped diarrhea and oocysts shedding (Madico et al., 1993, 1997). In Nepal, adults with cyclosporiasis were treated with TMP-SMX at 160-800 mg twice a day for 7 days; $84 \%$ of them were negative for oocysts upon stool examination whereas in the remainder the infection resolved extending therapy for an additional week (Hoge et al., 1995). In Haiti, HIV infected patients with cyclosporiasis were treated with TMP-SMX but $43 \%$ had recurrent infection. As a secondary prophylaxis, these patients received the drug three times a week for one month successfully controlling the infection
(Pape et al., 1994). For AIDS patients, the same dosage for 10 days and afterwards three times a week indefinitely is recommended (Guerrant et al., 2001).

As alternative treatments of cyclosporiasis, ciprofloxacin (Verdier et al., 2000) and in few cases nitazoxanide were effective for controlling infection (Diaz et al., 2003; Zimmer et al., 2007). The efficacy of these drugs is controversial. These drugs are usually recommened for treatment in patients that are sulpha allergic.

The close relatedness between Cyclospora spp. and Eimeria spp. suggests that many of the drugs used in the treatment of poultry coccidiosis may be effective against $C$. cayetanensis infection (Tang et al., 2015). Drugs affecting the mitochondrial and apicoplast metabolism could be developed and evaluated in clinical trials to test their effectiveness for cyclosporiasis (Saremy et al., 2011; Goodman et al., 2013; Stocks et al., 2014).

\subsubsection{Hygiene measures}

Improving personal and environmental sanitation may reduce exposure to human feces and contamination of the environment. Proper hygiene habits, and food washing and sanitizing may reduce the risk of acquiring infections. However, these practices do not completely remove Cyclospora oocysts from contaminated produce. Washing produce does not eliminate the risk of acquiring infection (Herwaldt et al., 1997, 1999). In fact, some oocysts remain on produce after washing (Ortega et al., 1997b). Good agricultural and manufacturing practice, and globally harmonized system are important to prevent introduction of the pathogen in the agricultural crops.

In the developing world, the most important steps to prevent infection are health education, personal hygiene, adequate hand washing, changing eating habits, safe drinking water, proper sanitary infrastructures, and treatment of human sewage. However, these steps are difficult challenges for low income-countries. Preventing geophagia in children is important because of the soilborne transmission of infection. The relationship between social marginalization and cyclosporiasis carries important implications for targeted public health interventions for infection in resource-poor groups. Great awareness of the parasite and increased familiarity with it or with the disease would improve surveillance programs for the coccidium and would increase the likelihood and early detection of future epidemics. It is necessary to implement detection techniques in the laboratories and in the field that would help to control the infection and prevent outbreaks locally and associated to imported contaminated produce in the developed world. Understanding interactions between socioeconomic and environmental conditions along with longitudinal and genotyping approaches will be the key to guiding prevention and control strategies to cyclosporiasis.

For prevention and control of waterborne Cyclospora infection, specific instructions and regulations developed by international organizations for controlling waterborne protozoa could be used for $C$. cayetanensis. From a public 
health perspective, potential spread of the parasite from water can be avoided only by adequate treatment of household water sources. Studies to assess the quality of stored water and household practices which stimulate posttreatment contamination are highly recommended. Consumers should be aware of risks associated with consumption of raw, unwashed leafy greens and berries. Boiled or filtered water must be used for drinking, food preparation, and washing of any fruits and vegetables that are eaten raw.

The use of wastewater and excreta in agricultural production may facilitate the dissemination of parasites and impact human health (Rimhanen-Finne et al., 2004); most common health risks are diarrheal diseases and soiltransmitted pathogens (Blumenthal et al., 2001). The identification of $C$. cayetanensis in wastewater (Sturbaum et al., 1998; Sherchand et al., 1999, 2001; Ben-Ayed et al., 2012) indicates that development of measures to minimize human exposure to this protist and to improve the safety of discharge and reuse of wastewater and sludge are needed. The use of untreated manure as a fertilizer on farms can lead to produce contamination when it is not treated properly. The quality of the water used for both irrigating produce and washing it after harvest is essential for preserving hygiene in farming operations. Farmers should be educated regarding the risks of using sewage and contaminated water in fertilizing and irrigating crops of fruits and vegetables. Toilet facilities should be provided for food pickers and handlers in place.

For the developed world, consumers should be aware of risks associated with consumption of raw, unwashed leafy greens and berries. Development, implementation and monitoring of on-farm control measures in endemic areas are necessary to diminish or avoid future epidemics locally and in non-endemic areas. Application of disinfection techniques for decontaminating imported produce will improve food quality and safety. However, as they are not available, prevention is the only option. Control methods should be devised for the potential routes used by the coccidium to enter the food production process. To prevent foodborne contamination, establishment of preventive or control measures in the processing and production operation is necessary for raw foods entering a factory or contamination of food products inside the factory (Dawson, 2005; Keller, 2009).

In the 2013-2015 US multistate outbreaks of cyclosporiasis (Table 2), some diseases were linked to fresh cilantro from Puebla, Mexico. As a consequence, the FDA and the government of Mexico enhanced the safety of fresh cilantro with produce safety controls on both sides of the border. The FDA implemented import controls to detain without physical examination shipments of fresh cilantro from the state of Puebla. Shipments of fresh cilantro from other states in Mexico will be allowed to enter into the US if documentation is submitted at entry demonstrating that the cilantro was harvested and packed outside of Puebla. The controls implemented by Mexico incorporate a system for risk reduction, including export controls, for cilantro from the state of Puebla. Mexico's Systems of Risk
Reduction of Contamination ensure that agriculture, aquaculture, seafood, and livestock products are produced and processed in optimal sanitary conditions to reduce the risk of contamination. Cilantro producers in the state of Puebla must comply with 11 minimal requirements on good agricultural and food safety practices (FDA, 2015). This collaborative effort will ensure that fresh fruits and vegetables are being prepared and stored under sanitary conditions.

In developed countries, the efficacy of conventional wastewater treatment processes at removing Cyclospora oocysts is limited (Galvan et al., 2013; Kitajima et al., 2014; Giangaspero et al., 2015b). Therefore, more advanced treatments must be used for further reduction of oocysts for reclamation purposes (Kitajima et al., 2014).

\subsection{Environmental Occurrence and Persistence}

\subsection{Detection Methods}

Cyclospora cayetanensis oocysts can be identified in clinical and environmental samples using microscopy and sporulation studies by trained technicians and parasitologsts. Molecular techniques can also be used. Samples can be stored in $2.5 \%$ aqueous potassium dichromate for molecular detection or sporulation and in $10 \%$ formalin for direct microscopy, concentration techniques, and staining. Cyclospora can be identified by bright-field or phase contrast microscopy in wet-mount preparations of fecal smears, but they are not easily distinguished from other particles (Mansfield and Gajadha, 2004. The oocysts stain variably with acid-fast techniques (Ortega et al., 1993) but stain uniformly with the safranin procedure modified by microwave treatment (Visvesvara et al.,1997) or with safranin at $85^{\circ} \mathrm{C}$ for 5 min using a water bath instead of microwave heating (Maratim et al., 2002).

Ultraviolet fluorescence microscopy is a useful technique for screening wet mounts of stool for Cyclospora oocysts which autofluoresce white-blue or green under epifluorescence microscopy using a 330-380 DM or 450-490 DM excitation filter, respectively (Ortega et al., 1993; Sterling et al., 1999). Concentration of the oocysts using ethyl acetate-formalin sedimentation, sucrose gradients, cesium chloride or discontinuous density Percoll gradients may be useful to maximize sensitivity and specificity of detection solely by microscopy (Kimura, 2004; Ortega et al., 2010).

The diagnosis of Cyclospora infection can also be confirmed by demonstrating sporulation of oocysts. If the sample is stored at 23 to $30^{\circ} \mathrm{C}$ for 1 to 2 weeks, the oocysts will differentiate into sporulated oocysts that contain two sporocysts (Ortega et al., 1994).

Limitations of traditional microscopy and morphological methods are the intermittent shedding of oocysts and the need to examine several fecal samples, variable staining of the parasite, and the time required for oocysts to sporulate for taxonomic classification; additionally, they require 
skilled microscopists, and does not allow for species identification. Currently, commercial immunofluorescent antibody kits are not available for Cyclospora.

Molecular biological tools have been developed to detect and differentiate Cyclospora at the species levels but they are not in widespread use for routine testing. These methods have greater sensitivity and specificity than microscopy for detection and diagnosis but they must be carefully designed and validated to avoid misidentifying closely related Eimeria species and robust enough for use in clinical and environmental matrices containing polymerase chain reaction (PCR) inhibitors and high levels of background DNA. Conventional PCR, PCR-fragment length polymorphism, and real-time quantitative PCR with melting curve analysis have been developed for detection of the parasite (Relman et al., 1996; Jinneman et al., 1998; Lalonde et al., 2008, 2011, 2013; Shields et al., 2003b; Varma et al., 2003). Application of a bead-based multiplex eukaryotic enteropathogens assay has also been developed. This multiplex PCR protocol provides a sensitive and specific assay for Cyclospora (Taniuchi, 2011; Buss et al., 2015).

Methodologies that could be used for fingerprinting analysis and genotype discrimination had not been available. The conserved sequence nature of rRNA and HSP70 genes and intra-isolate variations among different copies of ITS- 1 and ITS-2 had made the development of genotyping tools for the parasite difficult (Adam et al., 2000; Olivier et al., 2001; Riner et al., 2010; Zhou et al., 2011; Sulaiman et al., 2013, 2014). The recent availability of whole mitochondrial and apicoplast genome sequences (Tang et al., 2015; Qvarnstrom et al., 2015; Cinar et al., 2015) and whole genome sequencing (Liu et al., 2016) beyond rRNA and heat shock protein genes could facilitate development of genotyping tools for investigations of Cyclospora outbreaks. Recently, whole-genome sequence data from $C$. cayetanensis protozoa enabled the development of a MLST genotyping tool for characterizing isolates. In this study, 2 to 10 geographically segregated sequence types at each of 5 selected loci were observed. There was clear geographic clustering of MLST types. Most specimens from China clustered together in 1 major group, whereas specimens from epidemics in the US formed 2 other groups with specimens from Peru. A sample from Spain appeared to be different. The apparent existence of geographic clusters and the high resolution of the typing tool could be useful for infection/contamination source tracking (Guo et al., 2016).

Environmental samples are more difficult to examine than stool samples. The detection of any protozoan from any substrate follows a three-step process: concentration, purification using methods as immune-magnetic separation or density gradient centrifugation, and detection. The target pathogen has to be efficiently concentrated or the following procedures might not reveal the parasite. The third step is detection by several methods such as microscopy, flow cytometry, and nucleic acid amplification.

Methods to detect Cyclospora oocysts in environmental samples are limited. In water, the low frequency of the target requires large amounts of this matrix to be screened. Filtration using cartridge, hollow-fibre ultra-filters or capsule filters is performed to capture oocysts. High turbidity causes filters to clog. An alternative method of collection and concentration not affected by turbidity is flocculation (Vesey et al., 1993). Cyclospora can be isolated from water samples by filtration using Hannifin polypropylene cartridge filters or Envirocheck ${ }^{\circledR}$ capsules. Particles trapped in the filters are released using an elution buffer, and centrifuged. Pellets are stored in 2.5\% potassium dichromate and examined for the presence of the parasite (Sturbaum et al., 1998).

Limited availability of suspected food products and spotty distribution of oocysts present sampling difficulties; given the long incubation period of cyclosporiasis, little or no product may be available for testing (Shields et al., 2003a). A good elution method is necessary to retrieve oocysts from the suspected product. Due to the low infectious dose of $C$. cayetanensis and the unavailability of an enrichment procedure for this parasite, it is important to develop methods to maximize its detection. To recover the oocysts from food products, de-ionized water, saline solution, elution buffers, glycine buffer $\mathrm{pH}$ 5.5, 0.1\% Alconox, 3\% levulinic acid and 1\% HCL-pepsin, and lectin coated paramagnetic beads have been used (Lalonde et al., 2008; Shields et al., 2012; Chandra et al., 2014).

Recovery rates for certain products such as leafy vegetables and herbs, tend to be low, ranging from 12 to 14\% (Ortega et al., 1997b; Robertson et al., 2000). Detection limit can be as low as 0.3 oocysts per gram of raspberries (Orlandi et al., 2000) recoveries can be improved with better washing and detection techniques (Ortega et al., 1997b; Orlandi et al., 2000).

Molecular assays are a useful diagnostic tool in combination with oocyst extraction from water and foods. Nuclei acid amplification has been used for detecting $C$. cayetanensis in water (Shields et al., 2003b; Lalonde et al., 2008). Continuous separation channel centrifugation appears to be an efficient method for recovering Cyclospora oocysts but its main limitation is the availability of centrifuges (Borchardt et al., 2009).

To assess the potential risk of matrices contaminated with the parasite, the viability and sporulation stage of Cyclospora oocysts have to be determined. Due to a lack of vital dyes, tissue culture methods or animal models, viability assessments of $C$. cayetanensis oocysts in foods or water samples are often overlooked. Oocysts can be induced to sporulate in vitro between 8-14 days in distilled water or potassium dichromate at 22 to $30^{\circ} \mathrm{C}$ (Smith et al., 1997). The sporulated oocysts are treated with bile salts, sodium taurocholate and subjected to mechanical pressure to release sporozoites through excystation (Ortega et al., 1994; Smith et al., 1997). The viability and sporulation of Cyclospora oocysts have also been determined by the electron rotation method (Dalton et al., 2001). These methods work. However, when using environmental and food samples the number of parasites present are 
extremely low, making these methods hard if not impractical to use.

\subsection{Data on Occurrence}

In areas of endemicity where $C$. cayetanensis is common and water and sewage treatment systems, sanitary facilities, and standard housing developments are insufficient or lacking, oocysts can spread readily through water supplies and distribution systems, foods, and soil. The parasite has been isolated in developing and developed countries from several environmental matrices such as fresh produce, shellfish, drinking and recreational water, wastewater, and soil (Table 3).

\subsubsection{Sewage and wastewater}

In Perú, 72.7\% (8/11) of water samples from a primary oxidation lagoon contained Cyclospora oocysts (Sturbaum et al., 1998). Oocysts also were detected in sewage water in Nepal (Sherchand et al., 1999, 2001), and Tunisia (BenAyed et al., 2012). In Spain, oocysts were isolated in wastewater treatment plants with an annual prevalence of $16.1 \%(9 / 56)$ in raw water and $10.7 \%(6 / 56)$ in finished water. The highest prevalence was noted in spring (Galvan et al., 2013). In Italy, oocysts were detected in $21.3 \%$ (20/94) of wastewater samples, mainly in autumn (Giangaspero et al., 2015b). In the US (Arizona), oocysts were found in two wastewater treatment plants in raw and treated water (Kitajima et al., 2014).

\subsubsection{Sludge}

No data are available.

\subsubsection{Surface waters}

Water from rivers and lakes in Guatemala, Vietnam, Egypt, and Spain were positive for Cyclospora (Bern et al., 1999; Miegeville et al., 2003; el-Karamany et al., 2005; Galvan et al., 2013). In surface waters, oocyst occurrence may be highly variable with low frequency. The estimated concentration of the parasite in rivers from Guatemala was 15,000 or more oocysts per 10-liter specimen (Bern et al., 1999). In Egypt, the coccidium was isolated in five residential areas, from a drain, an irrigation canal, underground water and piped water, reflecting the high environmental contamination of the area. In the irrigation canal, the water contamination was 1900 oocysts / liter (elKaramany et al., 2005). In rivers and lakes samples from Vietnam, the level of positivity reached $63.6 \%$ (Miegeville et al., 2003). In four river basins in Spain, the annual prevalence of the parasite was $2 \%$ (Galvan et al., 2013).

\subsubsection{Ground waters}

Limited information of Cyclospora in ground water is available. In Egypt, the densities of contamination by oocysts / liter in underground water and piped water at shallow depth and underground water $>35 \mathrm{~m}$ deep were respectively 700 and zero (el-Karamany et al., 2005). In Italy, oocysts were identified in $6.2 \%(1 / 16)$ of well water samples (Giangaspero et al., 2015b).

\subsubsection{Drinking waters}

Oocysts have been detected in municipal drinking water that was associated with an outbreak in Nepal. The drinking water consisted of a mixture of municipal and river water. Coliform bacteria were not detected suggesting, perhaps like other coccida (eg. Cryptosporidium)that water chlorination is not sufficient to inactivate the coccidium (Rabold et al., 1994). In rural areas of Guatemala, C. cayetanensis was detected in 3 of 5 water samples used for public consumption by amplification of Cyclospora 18S-rDNA (Dowd et al., 2003). In Vietnam, oocysts were identified in drinking water (Miegeville et al., 2003). In Egypt, oocysts were isolated from drinking water in five residential areas (el-Karamany et al., 2005) and $0.24 \%(2 / 840)$ of surveyed drinking water samples from seven districts contained oocysts (Elshazly et al., 2007). In Ghana, Accra, 59.2\% (16/27) of sachets containing drinking water had oocysts (Kwakye-Nuako et al., 2007). In Italy, $30 \%(3 / 10)$ of tap water samples collected in a train were $C$. cayetanensis positive and contained copies of DNA corresponding to 4-11 oocysts per liter (Giangaspero et al., 2015a). This high concentration is a cause of concern for the possibility of presence of sporulated oocysts due to the high viability of Cyclospora oocysts (Smith et al., 1996) and the low infectious dose (Dixon et al., 2005).

Some have reported the presence of C.cayetanensis throughout the year in treated potable water from tanks (elKaramany et al., 2005) and treated piped water (Elshazly et al., 2007).Others have detected Cyclospora in drinking water, wastewater, and river water in Spain (Galvan et al., 2013), and in train tap water in Italy (Giangaspero et al., 2015a) being higher in spring months, even though differences in prevalence between the seasons were not statistically significant. In another study from Italy, the highest prevalence was in autumn in vegetables, wastewater, and soil (Giangaspero et al., 2015b).

\subsubsection{Seawater}

No data are available for the presence of $C$. cayetanensis oocysts in the marine environment. Detection of oocysts in shellfish in Alexandria, Egypt (Negm, 2003), and Izmir, Turkey (Aksoy et al., 2014) suggests contamination of coastal waters of these areas.

\subsubsection{Soil}

In a study from Apulia, Italy, $11.8 \%$ (6/51) of soil samples were found positive (Giangaspero et al., 2015b).

\subsubsection{Irrigation water and on crops}

Water used either for irrigation or processing of vegetables contained Cyclospora oocysts in Guatemala (Bern et al., 1999), Vietnam (Tram et al., 2008), and Italy (Giangaspero et al., 2015b). In Guatemalan raspberry fields, river water used for irrigation and application of pesticides contained oocysts and could have been the 
source of contamination of berries involved in several outbreaks in North America (Bern et al., 1999).

In Vietnam, $11.8 \%(34 / 288)$ of market water and herb samples and $8 \%(24 / 287)$ of farm samples were positive for Cyclospora including Vietnamese mint, marjoram, basil, lettuce, and coriander. Contamination was observed before the rainy season but not during this time (Tram et al., 2008).

Among fresh produce from markets in Peru, $C$. cayetanensis was detected on basil, cabbage, celery, cilantro, green onions, green chili, herbs, leeks, lettuce, and parsley (Ortega et al., 1997b). In Peru, of 110 vegetables examined, $1.8 \%$ (2) contained Cyclospora in one survey, and of 62 vegetables sampled in a second survey, $1.6 \%$ (1) contained oocysts (Ortega et al., 1997b). In Canada (Dixon et al., 2013), the US (Lopez et al. 2001), Costa Rica (Calvo et al., 2004), Venezuela (Devera et al., 2006), Nepal (Sherchand et al., 1999, 2001), Vietnam (Tram et al., 2008), Cambodia (Vuong et al., 2007), and Egypt (Abou el Naga, 1999; el Said, 2012), oocysts were detected on green leafy vegetables. In the US, the parasite was found in the raspberry filling of a cake (Ho et al., 2002). The report from Canada represents the first largescale surveillance study examining packaged ready- to-eat leafy greens in North America for the presence of protozoan parasites. A total of 544 samples were purchased from a variety of retail grocery stores in Ontario, Canada between April 2009 and March 2010; most of these products were grown in the US, with some from Canada and Mexico. A relatively high prevalence $(1.7 \%, 9 / 544)$ of Cyclospora spp. were identified by PCR-restriction fragment length (Dixon et al., 2013). This result established a baseline for further studies and suggested a need for more research in relation to the possible sources of contamination of these foods, the assessment of parasite viability and means to reduce foodborne transmission to humans.

In Costa Rica and Venezuela, the parasite was identified on lettuce. In Costa Rica, Cyclospora was detected during the dry season (Calvo et al., 2004; Devera et al., 2006). In Ghana, Cyclospora was isolated from cabbage, pepper, carrot, onion, tomato, and lettuce in $5 \%$ of the samples studied (Duedu et al., 2014). The relationship between numbers of organisms found on fresh produce and numbers in the environment in which crops were grown is unclear (Dawson, 2005).

Produce can become contaminated in the field, during harvesting, storage or transportation. Because of changes in processing, more precutting and coring of produce may occur in the field during harvest, increasing the probability for contamination (Sewell et al., 2001). Cyclospora oocysts present on produce also can originate in the soil where the food is grown and can be present in irrigation water or fertilizer. To prevent foodborne contamination establishment of preventive or control measures in the processing and production operation is necessary for raw foods entering a factory or contamination of food products inside the factory (Dawson, 2005; Keller, 2009). Enforcement of international food trade and implementation of methods using HACCP may help control cyclosporiasis (Buisson et al., 2008).

\subsubsection{Fish and shellfish}

No data are available for fish. Oocysts were detected in marketed shellfish in Alexandria, Egypt (Negm, 2003) and in farmed and wild mussels from Izmir Province, west coast of Turkey (Aksoy et al., 2014). Shellfish concentrate Cyclospora oocysts from contaminated waters. Controlled laboratory studies with freshwater clams (Corbicula fluminea) showed that 48 to $100 \%$ of the clams retained Cyclospora oocysts for up to 13 days (Graczyk et al., 1998). The parasite has been detected in shellfish in Egypt and Turkey (Negm, 2003; Aksoy et al., 2014).

\subsection{Persistence}

Cyclospora oocysts require several days to sporulate in the environment prior to being ingested by a susceptible host. This suggests that oocysts are quite hardy and environmentally resistant (Herwaldt, 2000). The oocysts require time, moisture, and moderate temperature (optimal $20-25^{\circ} \mathrm{C}$ ) to become infective (sporulate), thus following 7 to 15 days in a warm humid environment, sporulation occurs yielding infective oocysts and become infective. It has been suggested that oocyst suspension in water facilitates both the development and transmission of coccidian oocysts (Mansfield and Gajadha, 2004).

The percent sporulation of $C$. cayetanensis oocysts, as an indicator of viability, has been determined under a variety of conditions to examine persistence.

Whether Cyclospora oocysts are as resilient as other coccidian parasites is unknown. However, naturally occurring Cyclospora oocysts may survive for extended periods in the environment, given the marked seasonality of infection in endemic regions (Herwaldt et al., 1999). Little is known about the effects of environmental conditions on the rate of sporulation and on the viability of oocysts (Ortega et al., 1993; Smith et al., 1997; Herwaldt, 2000). Cyclospora oocysts may survive for extended periods, 7 days to 2 months, in water depending on the temperature (Ortega et al., 1998). No oocysts sporulated after storage at $4^{\circ} \mathrm{C}$ for 2 months and $1.3 \log _{10}$ reduction was seen (only $5 \%$ of the oocysts sporulated) at the highest temperature after 7 days $\left(37^{\circ} \mathrm{C}\right)$.

In other studies the equivalent of a $0.92 \log _{10}$ reduction was seen (very close to a T90) where by up to only $12 \%$ of the oocysts sporulated after being stored at $4^{\circ} \mathrm{C}$ for 1 to 2 months and this same level of reduction was seen at $30^{\circ} \mathrm{C}$ after 6-7 days (Smith et al., 1997).

Many more experiments were run with a yes or no result without quantification. For example viability of unsporulated oocysts were subjected to freezing and heating conditions in dairy and basil substrates and then placed in $2.5 \%$ potassium dichromate. Cyclospora sporulation was then observed to occur when Oocysts incubated at $23^{\circ} \mathrm{C}$ or stored at $4^{\circ} \mathrm{C}$ and then 
brought to $23^{\circ} \mathrm{C}$. (Note oocysts incubated at 30 or $37^{\circ} \mathrm{C}$, did not sporulate after various exposures (Sathyanarayanan et al. 2006).

The results of these studies showed that sporulation occurred for oocysts re-suspended in dairy substrates stored at $-15^{\circ} \mathrm{C}$ within $24 \mathrm{~h}$; in water or basil at $20^{\circ} \mathrm{C}$ for up to two days and at $37^{\circ} \mathrm{C}$ for up to 4 days. $C$. cayetanensis sporulation was also not affected after microwave heating for up to $45 \mathrm{~s}$ (Ortega et al., 2006). Few oocysts sporulated at $50^{\circ} \mathrm{C}$ for $1 \mathrm{~h}$ and sporulation did not occur at $-70,70$, and $100^{\circ} \mathrm{C}$ in water or basil leaves (Sathyanarayanan et al., 2006). These results were corroborated a number of times showing thatoocysts could not be induced to sporulate after freezing at $-18^{\circ} \mathrm{C}$ or $-20^{\circ} \mathrm{C}$ for $24 \mathrm{~h}$ or after heating at $60^{\circ} \mathrm{C}$ for $1 \mathrm{~h}$ (Sterling et al., 1999; Smith et al.,1997; Ortega et al., 1998).

Oocysts are very sensitive to desiccationand the oocyst wall ruptures after 15 min (Long et al., 1991).

\subsection{Reductions by Sanitation Management}

Very little is known about reductions of $C$. cayetanensis oocysts by sanitation management.

\subsection{Wastewater Treatment}

In a few studies the occurrence of oocysts before and after conventional wastewater treatment has been examined to evaluate processes for removing Cyclospora oocysts. However, no quantitative studies have reported log reductions.

In Spain, oocysts were isolated in conventional wastewater treatment plants with an annual prevalence of $16.1 \%(9 / 56)$ in raw sewage and $10.7 \%(6 / 56)$ in effluents (Galvan et al., 2013).

In Italy, significant differences were noted between the prevalence of contamination in treated wastewater samples (13\% positive) from a treatment plant with advanced technologies ( i.e. membrane ultrafiltration, GDF plus UV radiation) compared to one with traditional water treatment techniques $(55 \%$ of the samples positive $\mathrm{p}<0.003$ ) (Giangaspero et al., 2015b).

In the US, Arizona, oocysts were detected using qPCR methods in the influent with the highest concentration of $1.2 \times 10^{4} \mathrm{copies} / \mathrm{L}$. No concentrations in the effluent were noted in this work. The oocysts weredetected in $3 / 12$ samples (25\%) in the influent in two plants and $1 / 12$ and $2 / 12$ ( $8 \%$ and $17 \%)$ of the effluent samples. Also, the prevalence of Cyclospora in soil irrigated with effluents was higher than that at other sites in Italy (Giangaspero et al., 2015b).

The possibility of parasites such as Cyclospora surviving various biosolids treatments is low if temperatures reach above the $37^{\circ} \mathrm{C}$ in anaerobic digestion and achieve high dessication (See persistence above) as oocysts should not survive long under low-moisture conditions (Gerba et al., 2002). Yet studies validating this are not available.

\subsection{Disinfection}

Cyclospora oocysts seem to be resistant to many disinfectants, including chlorination at levels used in water treatment (Rabold et al., 1994; Soave et al., 1998).

Gaseous chlorine dioxide at $4.1 \mathrm{mg} / \mathrm{L}$ for $20 \mathrm{~min}$ (Ortega et al., 2008) did not affect sporulation of the oocysts (inoculated onto lettuce and basil).

High-hydrostatic-pressure processing and UV light radiation have been suggested to reduce the risk of cyclosporiasis associated with produce as observed using Eimeria acervulinaas a surrogate for Cyclospora (Kniel et al., 2007).

Oocysts are not killed when exposed to pesticides such as captan $50 \%$ wettable powder (W.P.), benomyl $50 \%$ W. P., diazinon $47.5 \%$, malathion $25 \%$ W.P., and zineb $75 \%$ W.P., at lower and higher than recommended doses, were not effective in inactivating oocyst sporulation (Sathyanarayanan et al., 2004). 


\section{References}

Abanyie, F., Harvey, R.R., Harris, J.R., Wiegand, R.E., Gaul, L., Desvignes-Kendrick, M. et al. (2013). Multistate outbreaks of Cyclospora cayetanensis infections associated with fresh produce: focus on the Texas investigations. Epidemiology and Infection. 143, pp. 3451-3458.

Adam, A. and Ortega, Y.R. (1999). Cyclospora. (Robinson, R.K., Batt, C.A. and Patel, P.D., ed.). Academic Press Limited. London, UK. pp. 502-513.

Adam, R.D., Ortega, Y.R., Gilman, R.H. and Sterling, C.R. (2000). Intervening transcribed spacer region 1 variability in Cyclospora cayetanensis. Journal of Clinical Microbiology. 38, pp. 2339-2343.

Aksoy, U., Marangi, M., Papini, R., Ozkoc, S., S Delibas, B. and Giangaspero, A. (2014). Detection of Toxoplasma gondii and Cyclospora cayetanensis in Mytilus galloprovincialis from Izmir Province coast (Turkey) by real time PCR/high resolution melting analysis (HRM). Food Microbiology. 44, pp. 128-135.

Aksoy, U. and Tunkay, S. (2007). Short communication: investigation of intestinal coccidia in patients with diarrhea. Mikrobiyoloji Bülteni. 41, pp. 127-135.

Al-Braiken, F.A., Amin, A., Beeching, N.J., Hommel, M. and Hart, C.A. (2003). Detection of Cryptoporidium amongst diarrhoeic and asymptomatic children in Jeddah, Saudi Arabia. Annals of Tropical Medicine and Parasitology. 97, pp. 505-510.

Al-Megrin, W.A. (2010). Intestinal parasites infection among immunocompromised patients in Riyadh, Saudi Arabia. Pakistan Journal of Biological Sciences. 13, pp. 390-394.

Alakpa, G.E., Clarke, S.C. and Fagbenro-Beyioku, A.F. (2003). Cyclospora cayetanensis in stools submitted in hospitals in Lagos, Nigeria. Clinical Microbiology and Infection. 9, pp. 731-733.

Albert, M.J., Kabir, I., Azim, T., Hossain, A., Ansaruzzaman, M. and Unicomb, L. (1994). Diarrhea associated with Cyclospora sp. in Bangladesh. Diagnostic Microbiology and Infectious Disease. 19, pp. 47-49.

Alfano-Sobsey, E.M., Eberhard, M.L.,., Weber, D.J., Won, K.Y., Nace, E.K. et al. (2004). Human challenge pilot study with Cyclospora cayetanensis. Emerging Infectious Diseases. 10, pp. 726-728.

Alva, S.B. (2005). Ciclosporosis: una parasitosis emergente (1) Aspectos clínicos y epidemiologicos. Revista de Gastroenterología del Perú. 25, pp. 328-335.

Arzuza, O.S., Arroyo, B.J., Villegas, S., Rocha, A. and Diaz, H. (2003). Infecciones parasitarias intestinales en pacientes positivos para el virus de la inmunodeficiencia humana (VIH) en la ciudad de Cartagena de Indias, Colombia. Revista de la Asociación Colombiana de Infectología. 7, pp. 58-63.

Ashford, R.W. (1979). Occurrence of an undescribed coccidian in man in Papua New Guinea. Annals of Tropical Medicine and Parasitology. 73, pp. 497-500.

Asma, I., Johari, S., Sim, B.L. and Lim, Y.A. (2011). How common is intestinal parasitism in HIV-infected patients in Malaysia?. Tropical Biomedicine. 28, pp. 400-410.

Ayala-Gaytan, J.J., Diaz-Olachea, C., Riojas-Montalvo, P. and Palacios-Martinez, C. (2004). Cyclosporidiosis: clinical and diagnostic characteristics of an epidemic outbreak. Revista de Gastroenterología de México. 69, pp. $226-229$.

Baldursson, S. and Karanis, P. (2011). Waterborne transmission of protozoan parasites: Review of worldwide outbreaks- An update 2004-2010. Water Research. 45, pp. 6603-6614.

Batz, M.B., Hoffmann, S. and Morris, Jr, J.G. (2012). Ranking the disease burden of 14 pathogens in food sources in the United States using attribution data from outbreak investigations and expert elicitation. Journal of Food Protection. 75, pp. 1278-1291. 
Becker, D.J., Oloya, J. and Ezeamama, A.E. (2015). Household socioeconomic and demographic correlates of Cryptosporidium seropositivity in the United States. PLoS Neglected Tropical Diseases. 9, pp. e0004080. doi: 10.1371/journal.pntd.0004080.

Bednarska, M., Bajer, A., Welc-Faleciak, R. and Pawelas, A. (2015). Cyclospora cayetanensis infection in transplant traveller: a case report of outbreak. Parasites and Vectors. 8, pp. 411.

Ben-Ayed, L., Yang, W., Widmer, G., Cama, V., Ortega, Y. and Xiao, L. (2012). Survey and genetic characterization of wastewater in Tunisia for Cryptosporidium spp., Giardia duodenalis, Enterocytozoon bieneusi, Cyclospora cayetanensis and Eimeria spp. Journal of Water and Health. 103, pp. 431-444.

Berlin, O.G., Novak, S.M., Porschen, R.K., Long, E.G., Stelma, G.N. and III, FW.Schaeffer (1994). Recovery of Cyclospora organisms from patients with prolonged diarrhea. Clinical Infectious Diseases. 18, pp. 606-609.

Bern, C., Hernandez, B., Lopez, M.B., Arrowood, M.J., M de Mejia, A., de Merida, A.M. et al. (1999). Epidemiologic studies of Cyclospora cayetanensis in Guatemala. Emerging Infectious Diseases. 5, pp. 766-774.

Bern, C., Ortega, Y.R., Checkley, W., Roberts, J.M., Lescano, A.G., Cabrera, L. et al. (2002). Epidemiologic differences between cyclosporiasis and cryptosporidiosis in Peruvian children. Emerging Infectious Diseases. 8, pp. 581-585.

Bhandari, D., Tandukar, S., Parajuli, H., Thapa, P., Chaudhary, P., Shrestha, D. et al. (2015). Cyclospora infection among the school children of Kathmandu, Nepal: prevalence and associated risk factors. Tropical Medicine and Health. 43, pp. 211-216.

Blans, M.C., Ridwan, B.U., Verweij, J.J., Rozenberg-Aroka, M. and Verhoef, J. (2005). Cyclosporiasis outbreaks, Indonesia. Emerging infectious diseases. 11, pp. 1453-1455.

Blumenthal, U.J., Cifuentes, E., Bennett, S., Quigley, M. and Ruiz-Palacios, G. (2001). The risk of enteric infections associated with wastewater reuse: the effect of season and degree of storage of wastewater. Transactions of the Royal Society of Tropical Medicine and Hygiene. 95, pp. 131-137.

Borchardt, M.A., Spencer, S.K., Bertz, P.D., Ware, M.W., Dubey, J.P. and Lindquist, HD.Alan (2009). Concentrating Toxoplasma gondii and Cyclospora cayetanensis from surface water and drinking water by continuous separation channel centrifugation. Journal of Applied Microbiology. 107, pp. 1089-1097.

Botero-Garces, J., Montoya-Palacio, M.N., Barguil, J.I. and Castaño-Gonzalez, A. (2006). Brote epidemico por Cyclospora cayetanensis en Medellin, Colombia. Revista de Salud Pública. 8, pp. 258-268.

Bouree, P., Lancon, A., Bisaro, F. and Bonnot, G. (2007). Six human cyclosporiasis: with general review. Journal of the Egyptian Society of Parasitology. 37, pp. 349-360.

Bouree, P., Lancon, A. and Bonnot, G. (2006). Une parasitose emergente: la cyclosporose. Revue a propos de five observations. Antibiotiques. 8, pp. 73-78.

Buisson, Y., Marie, J.L. and Davoust, B. (2008). These infectious diseases imported with food. Bulletin de la Société de Pathologie Exotique. 101, pp. 343-347.

Buss, B.F., Joshi, M.V., O'Keefe, A.L., Allensworth, C.D., Garvey, A., Obbink, K. et al. (2016). Regional investigation of a cyclosporiasis outbreak linked to imported romaine lettuce - Nebraska and Iowa, June-August 2013. Epidemiology and Infection. 144, pp. 1807-1817.

Buss, S.N., Leber, A., Chapin, K., Fey, P.D., Bankowski, M.J., Jones, M.K. et al. (2015). Multicenter evaluation of the BioFire FilmArray Gastrointestinal Panel for etiologic diagnosis of infectious gastroenteritis. Journal of Clinical Microbiology. 53, pp. 915-925.

Calvo, M., Carazo, M., Arias, M.L., Chaves, C., Monges, R. and Chinchilla, M. (2004). Prevalencia de Cyclospora sp., Cryptosporidium sp.,microsporidios y determinacion de coliformes fecales en frutas y vegetales frescos de consumo crudo en Costa Rica. Archivos Latinoamericanos de Nutrición. 54, pp. 428-432. 
Carollo, M.C., V Neto, A., Braz, L.M. and Dowoong, K. (2001). Pesquisa de oocistosde Cyclospora sp., em fezes de caes da Grande Sao Paulo, Estado de Sao Paulo, Brasil. Revista da Sociedade Brasileira de Medicina Tropical. 34, pp. 597-598.

Cazorla, D., Acosta, M.E. and Morales, P. (2012). Estudio clínico-epidemiológico de coccidiosis intestinales en una población rural de región semiárida del estado Falcón, Venezuela. Revista de Investigación Clínica. 53, pp. 273-288.

CDC (2015). Cyclosporiasis outbreak investigations-United States, 2015.

CDC (2014). Cyclosporiasis outbreak investigations-United States.

CDC (2009). Outbreaks updates for international cruise ships.

CDC (2004). Outbreak of cyclosporiasis associated with snow peas - Pennsylvania, 2004. Morbidity and Mortality Weekly Report (MMWR). 53, pp. 876-878.

CDC (1998). Outbreak of cyclosporiasis-Ontario, Canada, May 1998. Morbidity and Mortality Weekly Report (MMWR). 47, pp. 806-809.

Cedeño, T.C. (2002). Cyclospora cayetanensis: descripcion del primer caso en el Hospital San Rafael de Alajuela. Acta Médica Costarricense. 44, pp. 79-81.

Cegielski, J.P., Ortega, Y.R., McKee, S., Madden, J.F., Gaido, L., Schwartz, D.A. et al. (1999). Cryptosporidium, Enterocytozoon, and Cyclospora infections in pediatric and adult patients with diarrhea in Tanzania. Clinical Infectious Diseases. 28, pp. 314-321.

Chacin-Bonilla, L. (2010). Epidemiology of Cyclospora cayetanensis: A review focusing in endemic areas. Transactions of the Royal Society of Tropical Medicine and Hygiene. 115, pp. 181-193.

Chacin-Bonilla, L. (2008). Transmission of Cyclospora cayetanensis infection: a review focusing on soil-borne infection. Transactions of the Royal Society of Tropical Medicine and Hygiene. 102, pp. 215-216.

Chacin-Bonilla, L., Barrios, F. and Sanchez, Y. (2008). Environmental risk factors for Cryptosporidium infection in an island from Western Venezuela. Memórias do Instituto Oswaldo Cruz. 103, pp. 45-49.

Chacin-Bonilla, L., Barrios, F. and Sanchez, Y. (2007). Epidemiology of Cyclospora cayetanensis infection in San Carlos Island, Venezuela: strong association between socio-economic status and infection. Transactions of the Royal Society of Tropical Medicine and Hygiene. 101, pp. 1018-1024.

Chacin-Bonilla, L., De, M., Young, M. and Estevez, J. (2003). Prevalence and pathogenic role of Cyclospora cayetanensis in a Venezuelan community. American Journal of Tropical Medicine and Hygiene. 68, pp. 304-306.

Chacin-Bonilla, L., Estevez, J., Monsalve, F. and Quijada, L. (2001). Cyclospora cayetanensis infections among diarrheal patients from Venezuela. The American Journal of Tropical Medicine and Hygiene. 65, pp. 351-354.

Chacin-Bonilla, L., Panunzio, A.P., F Castillo, M., Cepeda, IE.Parra and Martinez, R. (2006). Microsporidiosis in Venezuela. Prevalence of intestinal microsporidiosis and its contribution to diarrhea in groups of human immunodeficiency virus infected patients from Zulia State. The American Journal of Tropical Medicine and Hygiene. 74, pp. 482-486.

Chambers, J., Somerfeldt, S., Mackey, L., Nichols, S., Ball, R., Roberts, D. et al. (1996). Outbreaks of Cyclospora cayetanensis infection-United States. MMWR. Morbidity Mortality Weekly Report. 45, pp. 549-551.

Chandra, V., Torres, M. and Ortega, Y.R. (2014). Efficacy of wash solutions in recovering Cyclospora cayetanensis, Cryptosporidium parvum, and Toxoplasma gondii from basil. Journal of Food Protection. 77, pp. 1348-1354.

Chu, D.M., Sherchand, J.B., Cross, J.H. and Orlandi, P.A. (2004). Detection of Cyclospora cayetanensis in animal fecal isolates from Nepal using an FTA filter-base polymerase chain reaction method. The American Journal of Tropical Medicine and Hygiene. 71, pp. 373-379. 
Cinar, H.N., Gopinath, G.K., Jarvis, K. and Murphy, H.R. (1015). The complete mitochondrial genome of the foodborne parasitic pathogen Cyclospora cayetanensis. PLoS One. 10, pp. e0128645. doi: 10.1371/journal.pone.0128645.

Clarke, S.C. and McIntyre, M. (1996). The incidence of Cyclospora cayetanensis in stool samples submitted to a district general hostipal. Epidemiology and Infection. 117, pp. 189-193.

Colley, D.G. (1996). Widespread foodborne cyclosporiasis outbreaks present major challenges. Emerg Infect Dis. 2, pp. 354-356.

Connor, B.A., Johnson, E.J. and Soave, R. (2001). Reiter syndrome following protracted symptoms of Cyclospora infection. Emerging Infectious Diseases. 7, pp. 453-454.

Connor, B.A., Reidy, J. and Soave, R. (1999). Cyclosporiasis: clinical and histopathological correlates. Clinical Infectious Diseases. 28, pp. 1216-12222.

Cordón, G.P., A Prados, H., Romero, D., M Moreno, S., Pontes, A., Osuna, A. et al. (2008). Intestinal parasitism in the animals of the zoological garden "Peña Escrita" (Almuñecar, Spain). Veterinary Parasitology. 156, pp. 302-309.

G Cordón, P., Prados, A.H., Romero, D., Moreno, M.S., Pontes, A., Osuna, A. et al. (2009). Intestinal and haematic parasitism in the birds of the Almuñecar (Granada, Spain) ornithological garden. Veterinary Parasitology. 165, pp. 361-366.

Dalton, C., Goater, A.D., Pethig, R. and Smith, H.V. (2001). Viability of Giardia intestinalis cysts and viability and sporulation state of Cyclospora cayetanensis oocysts determined by electrorotation. Applied and Environmental Microbiology. 67, pp. 586-590.

Dawson, D. (2005). Foodborne protozoan parasites. International Journal of Food Microbiology. 103, pp. $207-227$.

de Górgolas, M., Fortés, J. and Guerrero, ML.Fernández (2001). Cyclospora cayetanensis cholecystitis in a patient with AIDS. Annals of Internal Medicine. 16, pp. 134-166.

Deluol, A.M., Junod, C., Poirot, J.L., Heyer, F., N'go, Y. and Cosnes, J. (1994). Travellers diarrhea associated with Cyclospora sp. Journal of Eukaryotic Microbiology. 41, pp. 32S.

Devera, R., Blanco, Y., González, H. and Garcia, L. (2006). Parásitos intestinales en lechugas comercializadas en mercados populares y supermercados de Ciudad Bolívar, Estado Bolívar, Venezuela. Rev Soc Venezol Microbiol. 26, pp. 100-107.

Dias Borges, J., Rodriguez Alarcon, R.S., Amato Net, V. and Gakiya, E. (2009). Parasitoses intestinais de indigenas da comunidade Mapuera (Oriximina, Estado do Para, Brasil): elevada prevalencia de Blastocystis hominis and finding of Cryptosporidium sp. and Cyclospora cayetanensis. Revista da Sociedade Brasileira de Medicina Tropical. 42, pp. 348-350.

Diaz, E., Mondragon, J., Ramirez, E. and Bernal, R. (2003). Epidemiology and control of intestinal parasites with nitazoxanide in children in Mexico. The American Journal of Tropical Medicine and Hygiene. 68, pp. 384-385.

Dixon, B., Parrington, L., Cook, A., Pollari, F. and Farber, J. (2013). Detection of Cyclospora, Cryptosporidium, and Giardia in ready-to-eat packaged leafy greens in Ontario, Canada. Journal of Food Protection. 76, pp. 307-313.

Dixon, B.R., Bussey, J.M., Parrington, L.J. and Parenteau, M. (2005). Detection of Cyclospora cayetanensis oocysts in human fecal specimens by flow cytometry. Journal of Clinical Microbiology. 43, pp. 2375-2379.

Doller, P.C., Dietrich, K., Filipp, N., Brockmann, S., Dreweck, C., Vonthein, R. et al. (2002). Cyclosporiasis outbreak in Germany associated with the consumption of salad. Emerging Infectious Diseases. 8, pp. 922-994.

Dowd, S.E., John, D., Eliopolus, J., Gerba, C.P., Naranjo, J., Klein, R. et al. (2003). Confirmed detection of Cyclospora cayetanensis, Encephalitozoon intestinalis and Cryptosporidium parvum in water used for drinking. Journal of Water and Health. 1, pp. 117-123.

Drenaggi, D., Cirioni, O., Giacometti, A., Fiorentini, A. and Scalise, G. (1998). Cyclosporiasis in a traveler returning from 
South America. Journal of Travel Medicine. 5, pp. 153-155.

Duedu, K.O., Yarnie, E.A., Tetteh-Quarcoo, P.B., Attah, S.K., Donkor, E.S. and Ayeh-Kumi, P.F. (2014). A comparative survey of the prevalence of human parasites found in fresh vegetables sold in supermarkets and open-aired markets in Accra Ghana. BMC Research Notes. 7, pp. 836.

Eberhard, M.K., Owen, R.J., Bishop, H.S., de Almeida, M.E., Alex, J. and da Silva, A.J. (2014). Cyclospora spp. in drills, Bioko Island, Equatorial Guinea. Emerging Infectious Diseases. 20, pp. 510-511.

Eberhard, M.L., da Silva, A.J., Lilley, B.G. and Pieniazek, N.J. (1999). Morphologic and molecular characterization of new Cyclospora species from Ethiopian monkeys: C. cercopitheci sp.n., C. colobi sp.n, and C. papionis sp.n. Emerging Infectious Diseases. 5, pp. 651-658.

Eberhard, M.L., Nace, E.K. and Freeman, A.R. (1999). Survey for Cyclospora cayetanensis in domestic animals in an endemic area in Haiti. Journal of Parasitology. 85, pp. 562-563.

Eberhard, M.L., Nace, E.K., Freeman, A.R., Streit, T.G., da Silva, A.J. and Lammie, P.J. (1999). Cyclospora cayetanensis infections in Haiti: a common occurrence in the absence of watery diarrhea. The American Journal of Tropical Medicine and Hygiene. 60, pp. 584-586.

Eberhard, M.L., Ortega, Y.R., Hanes, D.E., Nace, E.K., Do, R.Q., Robl, M.G. et al. (2000). Attempts to establish experimental Cyclospora cayetanensis infection in laboratory animals. Journal of Parasitology. 86, pp. 577-582.

El-Karamany, E.M., Zaher, T.I. and El-Bahnasawy, M.M. (2005). Role of water in the transmission of cyclosporiasis in Sharkia Govemorate, Egypt. Journal of the Egyptian Society of Parasitology. 35, pp. 953-962.

Elshazly, A.M., Elsheikha, H.M., Soltan, D.M., Mohammad, K.A. and Morsy, T.A. (2007). Protozoal pollution of surface water sources in Dakahlia Govemorate Egypt. Journal of the Egyptian Society of Parasitology. 37, pp. 51-64.

Estran, C., Chaillou, S. and Marty, P. (2004). Un risque parasitaire pour le touriste en Republique Dominicaine: la cyclosporose. Journal of Medicine in the Tropics. 64, pp. 98-99.

C Fatni, el., Olmo, F., H Fatni, E., Romero, D. and Rosales, M.J. (2014). First genotyping of Giardia duodenalis and prevalence of enteroparasites in children from Tetouan (Morocco). Parasite. 21, doi: doi: 10.1051/parasite/2014049.

Fryauff, D.J., Krippner, R., Prodjodipuro, P., Ewald, C., Kawengian, S., Pegelow, K. et al. (1999). Cyclospora cayetanensis among expatriate and indigenous populations of West Java Indonesia. Emerging Infectious Diseases. 5, pp. 585-588.

Gajadhar, A.A., Lalonde, L.F., -Adhami, A., Singh, B.B. and Lobanov, V. (2015). Foodborne apicomplexan protozoa: Coccidia. Foodborne parasites in the food supply web: Occurrence and control. (Gajadhar, A.A., ed.). Elsevier. Cambridge, UK. pp. 101-148.

Galván, A.L., Magnet, A., Izquierdo, F., Fenoy, S., Rueda, C., C Vadillo, F. et al. (2013). Molecular characterization of human-pathogenic microsporidia and Cyclospora cayetanensis isolated from various water sources in Spain: a year-long longitudinal study. Applied and Environmental Microbiology. 79, pp. 449-459.

Garcia-Lopez, H.L., Rodriguez-Tovar, L.E. and de la Garza, CE.Medina- (1996). Identification of Cyclospora in poultry. Emerging Infectious Diseases. 2, pp. 356-357.

Gascon, J., Alvarez, M., Valls, M.E., Bordas, M.J., Jimenez de Anta, T.M. and Corachan, M. (2001). Cyclosporiasis: a clinical and epidemiological study in travellers with imported Cyclospora cayetanensis infection. Medicina Clinica. 116, pp. 451-464.

Gascon, J., Corachan, M., Bombi, J.A., Valls, M.E. and Bordes, J.M. (1995). Cyclospora in patients with traveller's diarrhea. Scandinavian Journal of Infectious Disease. 27, pp. 511-514.

Gascon, J., Corachan, M., Valls, M.E., Gene, A. and Bombi, J.A. (1993). Cyanobacteria-like body (CLB) in travellers with diarrhea. Scandinavian Journal of Infectious Disease. 25, pp. 253-257. 
Gerba, C.P., Pepper, I.L. and Whitehead, L.F. (2002). A risk assessment of emerging pathogens of concern in the land application of biosolids. Water Science and Technology. 46, pp. 224-230.

Gervelmeyer, A., Hempen, M., Nebel, U., Weber, C., Bronzwaer, S., Ammon, A. et al. (2008). Developing the community reporting system for foodborne outbreaks. Eurosurveillance. 6, pp. pii:19029.

Giangaspero, A., Marangi, M. and Arace, E. (2015). Cyclospora cayetanensis travels in tap water on Italian trains. Journal of Water and Health. 13, pp. 210-216.

Giangaspero, A., Marangi, M., Koehler, A.V., Papini, R., Normanno, G., Lacasella, V. et al. (2015). Molecular detection of Cyclospora in water, soil, vegetables and humans in southern Italy signals a need for improved monitoring by health authorities. International Journal of Food Microbiology. 211, pp. 95-100.

Gibbs, R.A., Nanyonjo, R., Pingault, N.M., Combs, B.G., Mazzucchelli, T., Armstrong, P. et al. (2013). An outbreak of Cyclospora infection on a cruise ship. Epidemiology and Infection. 141, pp. 508-516.

Goodman, C.D. and McFadden, G.I. (2013). Targeting apicoplasts in malaria parasites. Expert Opinion on Therapeutic Targets. 17, pp. 167-177.

Graczyk, T.K., Ortega, Y.R. and Conn, D.B. (1998). Recovery of waterborne oocysts of Cyclospora cayetanensis by Asian freshwater clams (Corbicula fluminea). The American Journal of Tropical Medicine and Hygiene. 59, pp. 928-931.

Green, S.T., McKendrick, M.W., Mohsen, A.H., Schmid, M.L. and Prakasam, S.F. (2000). Two simultaneous cases of Cyclospora cayetanensis enteritis returning from Dominican Republic. Journal of Travel Medicine. 7, pp. 41-42.

Guerrant, R.L., DeBoer, M.D.,., Scharf, R.J. and Lima, A.A. (2013). The impoverished gut-a triple burden of diarrhoea, stunting and chronic disease. Nat Rev Gastroenterol Hepatol. 10, pp. 220-229.

Guerrant, R.L., Van Gilder, T., Steiner, T.S., Thielman, N.M., Slutsker, L.,, et al. (2001). Practice guidelines for the management of infectious diarrhea. Clinical Infectious Diseases. 32, pp. 331-351.

Guo, Y., Roellig, D.M., Li, N., Tang, K., Frace, M., Ortega, Y. et al. (2016). Multilocus sequence typing tool for Cyclospora cayetanensis. Emerging Infectious Diseases. 22, pp. 1464-1467.

Gupta, A.K. (2011). Intestinal coccidian parasitic infections in rural community in and around Loni, Maharashtra. Journal of Parasitic Diseases. 35, pp. 54-56.

Guzman-Herrador, B., Carlander, A., Ethelberg, S., B de Blasio, F., Kuusi, M., Lund, V. et al. (2015). Waterborne outbreaks in the Nordic countries, 1998 to 2012. Eurosurveillance.

Hale, D., Aldeen, W. and Carroll, K. (1994). Diarrhea associated with Cyanobacteria- like bodies in an immunocompetent host. An unusual epidemiological source. JAMA. 271, pp. 144-145.

Hall, R.L., Jones, J.L. and Herwaldt, B.L. (2011). Surveillance for laboratory-confirmed sporadic cases of cyclosporiasisUnited States, 1997-2008. MMWR. Morbidity Mortality Weekly Report. Surveillance Summaries. 60, pp. 1-11.

Hall, R.L., Jones, J.L., Hurd, S., Smith, G., Mahon, B.E. and Herwaldt, B.L. (2012). Population-based active surveillance for Cyclospora infection-United States, Foodborne Diseases Active Surveillance Network (FoodNet),1997-2009. Clinical Infectious Diseases. 54(Suppl.), pp. S411-417.

Hammond, R. (2005). Cyclospora outbreak in Florida, 2005. Food-borne Threats Health Policies Pract Surveill Prev. Outbreak Invest. Int. Coord. Workshop. S15,.

Haque, R., Mondal, D., Kirkpatrick, B.D., Akther, S., Farr, B.M., R Sack, B. et al. (2003). Epidemiologic and clinical characteristics of acute diarrhea with emphasis on Entamoeba histolytica infections in preschool children in an urban slum of Dhaka, Bangladesh. The American Journal of Tropical Medicine and Hygiene. 69, pp. 398-405.

Herwaldt, B.L. (2006). The ongoing saga of U.S. outbreaks of cyclosporiasis associated with imported fresh produce: what 
Cyclospora cayetanensis has taught us and what we have yet to learn. Addressing foodborne threats to health: policies, practices, and global coordination. Institute ed. National Academic Press. Washington, DC. pp. 85-115, 133-140.

Herwaldt, B.L. (2000). Cyclospora cayetanensis: a review, focusing on the outbreaks of cyclosporiasis in the 1990s. Clinical Infectious Diseases. 31, pp. 1040-1057.

Herwaldt, B.L. and Ackers, M.L. (1997). An outbreak in 1996 of cyclosporiasis associated with imported raspberries. The New England Journal of Medicine. 336, pp. 1548-1556.

Herwaldt, B.L. and Beach, M.J. (1999). The return of Cyclospora in 1997: another outbreak of cyclosporiasis in North America associated with imported raspberries. Annals of Internal Medicine. 130, pp. 210-220.

Hoang, L.M., Fyfe, M., Ong, C., Harb, J., Champagne, S., Dixon, B. et al. (2005). Outbreak of cyclosporiasis in British Columbia associated to imported Thai basil. Epidemiology and Infection. 133, pp. 23-27.

Ho, A.Y., Lopez, A.S., Eberhart, M.G., Levenson, R., Finkel, B.S., da Silva, A.J. et al. (2002). Outbreak of cyclosporiasis associated with imported raspberries, Philadelphia, Pennsylvania, 2000. Emerging Infectious Diseases. 8, pp. 783-788.

Hoge, C.W., Echeverria, P., Rajah, R., Jacobs, J., Malthouse, S., Chapman, E. et al. (1995). Prevalence of Cyclospora species and other enteric pathogens among children less than 5 years of age in Nepal. Journal of Clinical Microbiology. 33, pp. 3058-3060.

Hoge, C.W., Shlim, D.R., Rajah, R., Triplett, J., Shear, M., Rabold, J.G. et al. (1993). Epidemiology of diarrhoeal illness associated with coccidian-like organism among travellers and foreign residents in Nepal. Lancet. 341, pp. 1175-1179.

Huang, P., Weber, J.T., Sosin, D.M., Griffin, P.M., Long, E.G., Murphy, J.J. et al. (1985). The first reported outbreak of diarrheal illness associated with Cyclospora in the United States. Annals of Internal Medicine. 123, pp. 409-414.

Insulander, M., Svenungsson, B., Lebbad, M., Karlsson, L. and De Jong, B. (2010). A foodborne outbreak of Cyclospora infection in Stockholm, Sweden. Foodborne Pathogens and Disease. 7, pp. 1585-1587.

Iqbal, J., Hira, P.R., Al-Ali, F. and Khalid, N. (2011). Cyclospora cayetanensis: first report of imported and autochthonous infections in Kuwait. The Journal of Infection in Developing Countries. 5, pp. 383-390.

Jinneman, K.C., Wetherington, J.H., Hill, W.E., Adams, A.M., Johnson, J.M., Tenge, B.J. et al. (1998). Template preparation for PCR and RFLP of amplification products for the detection and identification of Cyclospora sp. and Eimeria spp. oocysts directly from raspberries. Journal of Food Protection. 61, pp. 1497-1503.

Kaminsky, R.G. (2002). Comparacion epidemiologica entre apicomplexa intestinales en poblacion hospitalaria en Honduras. Revista médica hondureña. 70, pp. 164-172.

Karaman, U., Daldal, N., Ozer, A., Enginyurt, O. and Erturk, O. (2015). Epidemiology of Cyclospora species in humans in Malatya Province in Turkey. Jundishapur Journal of Microbiology. 8, pp. e18661. doi: 10.5812/jjm.18661v2. eCollection 2015.

Karanis, P., Kourenti, C. and Smith, H. (2007). Waterborne transmission of protozoan parasites: a worldwide review of outbreaks and lessons learnt. Journal of Water and Health. 5, pp. 1-38.

Keller, S.E. (2009). Microbial contamination of fresh produce. Intentional and unintentional contaminants in food and feed, vol 1020. American Chemical Society. Washington, DC. pp. 25-45.

Kimura, K., Hane, Y., Watanabe, Y., Amy, G. and Ohkuma, N. (2004). Irreversible membrane fouling during ultrafiltration of surface water. Water Research. 38, pp. 3431-3441.

Kimura, K., Rai, S.K., Rai, G., Insisiengmay, S., Kawabata, M., Karanis, P. et al. (2005). Study on Cyclospora cayetanensis, associated with diarrheal disease in Nepal and Lao PDR. Southeast Asian Journal of Tropical Medicine and Public Health. 36, pp. 1371-1376. 
Kitajima, M., Haramoto, E., Iker, B.C. and Gerba, C.P. (2014). Occurrence of Cryptosporidium, Giardia, and Cyclospora in influent and effluent water at wastewater treatment plants in Arizona. Science of the Total Environment. 484, pp. 129-136.

Kniel, K.E., Shearer, A.E., Cascarino, J.L., Wilkins, G.C. and Jenkins, M.C. (2007). High hydrostatic pressure and UV light treatment of produce contaminated with Eimeria acervulina as a Cyclospora cayetanensis surrogate. Journal of Food Protection. 70, pp. 2837-2842.

Koumans, E.H., Katz, D.J., Malecki, J.M., Kumar, S., Wahlquist, S.P., Arrowood, M.J. et al. (1998). An outbreak of cyclosporiasis in Florida in 1995: a harbinger of multistate outbreaks in 1996 and 1997. The American Journal of Tropical Medicine and Hygiene. 59, pp. 235-242.

Kozak, G.K., MacDonald, D., Landry, L. and Farber, J.M. (2013). Foodborne outbreaks in Canada linked to produce: 2001 through 2009. Journal of Food Protection. 76, pp. 173-183.

Kurniawan, A., Karyadi, T., Dwintasari, S.W., Sari, I.P., Yunihastuti, E., Djauzi, S. et al. (2009). Intestinal parasitic infections in HIV/AIDS patients presenting with diarrhoea in Jakarta, Indonesia. Transactions of the Royal Society of Tropical Medicine and Hygiene. 103, pp. 892-898.

Kwakye-Nuako, G., Borketey, P., Mensah-Attipoe, I., Asmah, R. and Ayeh-Kumi, P. (2007). Sachet drinking water in Accra: the potential threats of transmission of enteric pathogenic protozoan organisms. Ghana Medical Journal. 41, pp. 62-67.

Lainson, R. (2005). The genus Cyclospora: (Apicomplexa: Eimeriidae), with a description of Cyclospora schneideri n.sp. in the snake Anilius scytale (Anilüdae) from Amazonian Brazil - a review. Memorias do Instituto Oswaldo Cruz. 100, pp. 103-115.

Lalonde, L.F. and Gajadhar, A.A. (2011). Detection and differentiation of coccidian oocysts by real-time PCR and melting curve analysis. Journal of Parasitology. 97, pp. 725-730.

Lalonde, L.F. and Gajadhar, A.A. (2008). Highly sensitive and specific PCR assay for reliable detection of Cyclospora cayetanensis oocysts. Applied and Environmental Microbiology. 74, pp. 4354-4358.

Lalonde, L.F., Reyes, J. and Gajadhar, A.A. (2013). Application of a qPCR assay with melting curve analysis for detection and differentiation of protozoan oocysts in human fecal samples from Dominican Republic. The American Journal of Tropical Medicine and Hygiene. 89, pp. 892-898.

Lebbad, M. and Linder, E. (1993). Newly discovered organism behind diarrhea. All patients had recently been abroad. Lakartidningen. 90, pp. 951-952.

Li, G., Xiao, S., Zhou, R., Li, W. and Wadeh, H. (2007). Molecular characterization of Cyclospora-like organism from dairy cattle. Parasitology Research. 100, pp. 955-961.

Li, N., Ye, J., Arrowood, M.J., Ma, J., Wang, L., Xu, H. et al. (2015). Identification and morphologic and molecular characterization of Cyclospora macacae n. sp. from rhesus monkeys in China. Parasitology Research. 114, pp. 1811-1816.

Liu, H., Shen, Y., Yin, J., Yuan, Z., Jiang, Y., Xu, Y. et al. (2014). Prevalence and genetic characterization of Cryptosporidium, Enterocytozoon, Giardia and Cyclospora in diarrheal outpatients in China. BMC Infectious Diseases. 14, doi: 10.1186/1471-2334-14-25.

Liu, S., Wang, L., Zheng, H., Xu, Z., Roellig, D.M., Li, N. et al. (2016). Comparative genomics reveals Cyclospora cayetanensis possesses coccidia-like metabolism and invasion components but unique surface antigens. BMC Genomics. 30, pp. 17-316. doi: 10.1186/s12864-016-2632-3.

Long, E.G., White, E.H., Carmichael, W.W., Quinlisk, P.M., Raja, R., Swisher, B.L. et al. (1991). Morphological and staining characteristics of a Cyanobacterium-like organism associated with diarrhea. The Journal of Infectious Diseases. 164, pp. 199-202.

Lopez, A.S., Bendik, J.M., Alliance, J.Y., Roberts, J.M., da Silva, A.J., Moura, I.N. et al. (2003). Epidemiology of Cyclospora cayetanensis and other intestinal parasites in a community in Haiti. Journal of Clinical Microbiology. 41, pp. 2047-2054. 
Lopez, A.S., Dodson, D.R., Arrowood, M.J., Jr, PA.Orlandi, da Silva, A.J., Bier, J.W. et al. (2001). Outbreak of cyclosporiosis associated with basil in Missouri in 1999. Clinical Infectious Diseases. 32, pp. 1010-1017.

Madico, G., Gilman, R.H., Miranda, E., Cabrera, L. and Sterling, C.R. (1993). Treatment of Cyclospora infections with cotrimoxazole. Lancet. 342, pp. 122-123.

Madico, G., McDonald, J., Gilman, R.H., Cabrera, L. and Sterling, C.R. (1997). Epidemiology and treatment of Cyclospora cayetanensis infection in Peruvian children. Clinical Infectious Diseases. 24, pp. 977-981.

Mansfield, L.S. and Gajadhar, A.A. (2004). Cyclospora cayetanensis, a food- and waterborne coccidian parasite. Veterinary Parasitology. 126, pp. 73-90.

Maratim, A.C., Kamar, K.K., Ngindu, A., Akoru, C.N., Diero, L. and Sidle, J. (2002). Safranin staining of Cyclospora cayetanensis oocysts not requiring microwave heating. British Journal of Biomedical Science. 59, pp. 114-115.

Markus, M.B. and Frean, J.A. (1993). Occurrence of human Cyclospora infection in sub-Saharan Africa. South African Medical Journal. 83, pp. 862-863.

Mead, P.S., Slutsker, L., Dietz, V., McCaig, L.F., Bresee, J.S., Shapiro, C. et al. (1999). Food-related illness and death in the United States. Emerging Infectious Diseases. 5, pp. 607-625.

Miegeville, M., Koubi, V., Dan, L.C., Barbier, J.P. and Cam, P.D. (2003). Cyclospora cayetanensis presence in aquatic surroundings in Hanoi (Vietnam). Environmental study (well water, lakes and rivers). Bulletin de la Société de Pathologie Exotique. 96, pp. 149-152.

Mundaca, C.C., Torres-Slimming, P.A., Araujo-Castillo, R.V., Moran, M., Bacon, D.J., Ortega, Y. et al. (2008). Use of PCR to improve diagnostic yield in an outbreak of cyclosporiasis in Lima Peru. Transactions of the Royal Society of Tropical Medicine and Hygiene. 102, pp. 712-717.

Naga, IF.Abou el (1999). Studies on a newly emerging protozoal pathogen: Cyclospora cayetanensis. Journal of the Egyptian Society of Parasitology. 29, pp. 575-586.

Nassef, N.E., El-Ahl, S.A., El-Shafee, O.K. and Nawar, M. (1998). Cyclospora: a newly identified protozoan pathogen of man. Journal of the Egyptian Society of Parasitology. 28, pp. 213-219.

Negm, A.Y. (2003). Human pathogenic protozoa in bivalves collected from local markets in Alexandria. Journal of the Egyptian Society of Parasitology. 33, pp. 991-998.

Nichols, G.L., Freedman, J., Pollock, K.G., Rumble, C., Chalmers, R.M., Chiodini, P. et al. (2015). Cyclospora infection linked to travel to Mexico, June to September 2015. Eurosurveillance. 20, doi: 10.2807/15607917.ES.2015.20.43. 30048.

Nimri, L.F. (2003). Cyclospora cayetanensis and other intestinal parasites associated with diarrhea in rural area of Jordan. International Microbiology. 6, pp. 131-135.

Nsagha, D.S., Njunda, A.L., Assob, N.J., Ayima, C.W., Tanue, E.A., Kibu, O.D. et al. (2016). Intestinal parasitic infections in relation to $\mathrm{CD} 4(+) \mathrm{T}$ cell counts and diarrhea in HIV/AIDS patients with or without antiretroviral therapy in Cameroon. BMC Infectious Diseases. 16, doi: 10.1186/s12879-016-1337-1.

Nuñez, F.A., Gonzalez, O.M., Gonzalez, I., Escobedo, A.A. and Cordovi, R.A. (2003). Intestinal coccidia in Cuban pediatric patients with diarrhea. Memorias do Instituto Oswaldo Cruz. 98, pp. 539-542.

Ogedengbe, M.E., Qvarnstrom, Y., da Silva, A.J., Arrowood, M.J. and,. (2015). A linear mitochondrial genome of Cyclospora cayetanensis (Eimeriidae, Eucoccidiorida, Coccidiasina, Apicomplexa) suggests the ancestral start position within mitochondrial genomes of eimeriid coccidia. International Journal for Parasitology. 45, pp. 361-365.

Olivier, C., van de Pas, S., Lepp, P.W., Yoder, K. and Relman, D.A. (2001). Sequence variability in the first internal transcribed spacer region within and among Cyclospora species is consistent with polyparasitism. International Journal for Parasitology. 31, pp. 1475-1487. 
Ooi, W.W., Zimmerman, S.K. and Needham, C.A. (1995). Cyclospora species as a gastrointestinal pathogen in immunocompetent hosts. Journal of Clinical Microbiology. 33, pp. 1267-1269.

Orlandi, P.A. and Lampel, K.A. (2000). Extraction-free, filter-based template preparation for rapid and sensitive PCR detection of pathogenic parasitic protozoa. Journal of Clinical Microbiology. 38, pp. 2271-2277.

Orozco-Mosqueda, G.E., Martínez-Loya, O.A. and Ortega, Y.R. (2014). Cyclospora cayetanensis in a pediatric hospital in Morelia, México. The American Journal of Tropical Medicine and Hygiene. 91, pp. 537-540.

Ortega, Y.R., Gilman, R.H. and Sterling, C.R. (1994). A new coccidian parasite Apicomplexa: Eimeriidae from humas. Journal of Parasitology. 80, pp. 625-629.

Ortega, Y.R. and Liao, J. (2006). Microwave inactivation of Cyclospora cayetanensis sporulation and viability of Cryptosporidium parvum. Journal of Food Protection. 69, pp. 1957-1960.

Ortega, Y.R., Mann, A., Torres, M.P. and Cama, V. (2008). Efficacy of gaseous chlorine dioxide as a sanitizer against Cryptosporidium parvum, Cyclospora cayetanensis, and Encephalitozoon intestinalis on produce. Journal of Food Protection. 71, pp. 2410-2414.

Ortega, Y.R., Nagle, R., Gilman, R.H., Watanabe, J., Miyagui, J., Quispe, H. et al. (1997). Pathologic and clinical findings in patients with cyclosporiasis and a description of intracellular parasite life-cycle stages. The Journal of Infectious Diseases. 176, pp. 1584-1589.

Ortega, Y.R., Roxas, C.R., Gilman, R.H., Miller, N.J., Cabrera, L., Taquiri, C. et al. (1997). Isolation of Cryptosporidium parvum and Cyclospora cayetanensis from vegetables collected in markets of an endemic region in Peru. The American Journal of Tropical Medicine and Hygiene. 57, pp. 683-686.

Ortega, Y.R. and Sanchez, R. (2010). Update on Cyclospora cayetanensis, a food-borne and waterborne parasite. Clinical Microbiology Reviews. 23, pp. 218-234.

Ortega, Y.R., Sterling, C.R. and Gilman, R.H. (1998). Cyclospora cayetanensis. Advances in Parasitology. 40, pp. 399-418.

Ortega, Y.R., Sterling, C.R., Gilman, R.H., Cama, V.A. and Diaz, F. (1993). Cyclospora species a new protozoan pathogen of humans. The New England Journal of Medicine. 328, pp. 1308-1312.

Ozdamar, M.T., Turkoglu, S. and Hakko, E. (2008). Outbreak of cyclosporiasis in Istanbul, Turkey during an extremely dry and warm summer. Abstr. 18th Cong. European Journal of Clinical Microbiology and Infectious Diseases. pp. 988.

Pape, J.W., Verdier, R.I., Boncy, M., Boncy, J. and Johnson, W.D. (1994). Cyclospora infection in adults infected with HIV. Clinical manifestations, treatment, and prophylaxis. Annals of Internal Medicine. 121, pp. 654-657.

PHAC (2015). Public health notice update - outbreak of Cyclospora under investigation. Public Health Agency of Canada. Ottawa, Canada.

PHAC (2007). 2005 Annual laboratory surveillance data for enteric pathogens in Canada. Public Health Agency of Canada. Ottawa, Canada.

PHAC (2006). 2004. Annual laboratory surveillance data for enteric pathogens in Canada. Public Health Agency of Canada. Ottawa, Canada.

Public Health Agency of Canada (PHAC). (1997). Update: outbreaks of cyclosporiasis - United States and Canada. Canada Communicable Disease Report. 2, pp. 143-144.

Pham-Duc, P., Nguyen-Viet, H., Hattendorf, J., Zinsstag, J., Phung-Dac, C., Zurbrügg, C. et al. (2013). Ascaris lumbricoides and Trichuris trichiura infections associated with wastewater and human excreta use in agriculture in Vietnam. International Journal for Parasitology. 62, pp. 172-180.

Pollok, R.C., Bendall, R.P., Moody, A., Chiodini, P.L. and Churchill, D.R. (1992). Traveller's diarrhoea associated with 
cyanobacterium-like bodies. Lancet. 340, pp. 556-557.

Puente, S., Morente, A., Garcia-Benayas, T., Subirats, M., Gascon, J. and Gonzalez-Lahoz, J.M. (2006). Cyclosporiasis: a point source outbreak acquired in Guatemala. Journal of Travel Medicine. 13, pp. 334-337.

Qvarnstrom, Y., Wei-Pridgeon, Y., Li, W., Nascimento, F.S., Bishop, H.S., Herwaldt, B.L. et al. (2015). Draft genome sequences from Cyclospora cayetanensis oocysts purified from a human stool sample. Genome Announcements. 3, pp. e01324-15. doi: 10.1128/genomeA.01324-15.

Rabold, J.G., Hoge, C.W., Shlim, D.R., Kefford, C., Rajah, R. and Echeverria, P. (1994). Cyclospora outbreak associated with chlorinated drinking water. Lancet. 344, pp. 1360-1361.

Relman, D.A., Schmidt, T.M., Gajadhar, A., Sogin, M., Cross, J., Yoder, K. et al. (1996). Molecular phylogenetic analysis of Cyclospora, the human intestinal pathogen, suggests that it is closely related to Eimeria species. The Journal of Infectious Diseases. 173, pp. 440-445.

Ribes, J.A., Seabolt, J.P. and Overman, S.B. (2004). Point prevalence of Cryptosporidium, Cyclospora, and Isospora infections in patients being evaluated for diarrhea. American Journal of Clinical Nutrition. 122, pp. 28-32.

Richardson, Jr, R.F., Remler, B.F., Katirji, B. and Murad, M.H. (1998). Guillain-Barré syndrome after Cyclospora infection. Muscle Nerve. 21, pp. 669-671.

Rijpstra, A.C. and Laarman, J.J. (1993). Repeated findings of unidentified small Isospora-like coccidia in faecal specimens from travellers returning to The Netherlands. Tropical and geographical medicine. 45, pp. 280-282.

Rimhanen-Finne, R., Vuorinen, A., Marmo, S., Malmberg, S. and Hänninen, M.L. (2004). Comparative analysis of Cryptosporidium, Giardia and indicator bacteria during sewage sludge hygienization in various composting processes. Letters in Applied Microbiology. 38, pp. 301-305.

Riner, D.K., Nichols, T., Lucas, S.Y., Mullin, A.S., Cross, J.H. and Lindquist, H.D. (2010). Intragenomic sequence variation of the ITS-1 region within a single flow-cytometry-counted Cyclospora cayetanensis oocysts. Journal of Parasitology. 96, pp. 914-919.

Robertson, L.J., Gjerde, B. and Campbell, A.T. (2000). Isolation of Cyclospora oocysts from fruits and vegetables using lectin-coated paramagnetic beads. Journal of Food Protection. 63, pp. 1410-1414.

Roldan, W.H., Espinoza, Y.A., Huapaya, P.E., Huiza, A.F., Sevilla, C.R. and Jimenez, S. (2009). Frequency of human toxocariasis in a rural population from Cajamarca Peru determined by dot-Elisa test. Revista do Instituto de Medicina Tropical de São Paulo. 51, pp. 57-71.

Sadaka, H.A. and Zoheir, M.A. (2001). Experimental studies on cyclosporiosis. Journal of the Egyptian Society of Parasitology. 31, pp. 65-77.

D Said, el. (2012). Detection of parasites in commonly consumed raw vegetables. Alexandria Journal of Medicine. 48, pp. 345-352.

Saremy, S., Boroujeni, M.E., Bhattacharjee, B., Mittal, V. and Chatterjee, J. (2011). Identification of potential apicoplast associated therapeutic targets in human and animal pathogen Toxoplasma gondii ME49. Bioinformation. 7, pp. 379-383.

Sathyanarayanan, L. and Ortega, Y. (2006). Effects of temperature and different food matrices on Cyclospora cayetanensis oocyst sporulation. Journal of Parasitology. 92, pp. 218-222.

Sathyanarayanan, L. and Ortega, Y. (2004). Effects of pesticides on sporulation of Cyclospora cayetanensis and viability of Cryptosporidium parvum. Journal of Food Protection. 67, pp. 1044-1049.

Scallan, E., Griffin, P.M., Angulo, F.J., Tauxe, R.V. and Hoekstra, R.M. (2011). Foodborne illness acquired in the United States-unspecified agents. Emerging Infectious Diseases. 17, pp. 16-22. 
Scharf, R.L. (2012). Economic burden from health losses due to foodborne illness in the United States. Journal of Food Protection. 75, pp. 123-131.

Sewell, A.M. and Farber, J.M. (2001). Foodborne outbreaks in Canada linked to produce. Journal of Food Protection. 64, pp. 1863-1877.

Shah, L., MacDougall, L., Ellis, A., Ong, C., Shyng, S. and LeBlanc, L;.British Co (2009). Challenges of investigating community outbreaks of cyclosporiasis. Emerging Infectious Diseases. 15, pp. 1286-1288.

Sherchand, J.B. and Cross, J.H. (2001). Emerging pathogen Cyclospora cayetanensis infection in Nepal. Southeast Asian Journal of Tropical Medicine and Public Health. 32, pp. 143-150.

Sherchand, J.B., Cross, J.H., Jimba, M., Sherchand, S. and Shrestha, M.P. (1999). Study of Cyclospora cayetanensis in health care facilities, sewage water and green leafy vegetables in Nepal. Southeast Asian Journal of Tropical Medicine and Public Health. 30, pp. 58-63.

Shields, J.M., Lee, M.M. and Murphy, H.R. (2012). Use of a common laboratory glassware detergent improves recovery of Cryptosporidium parvum and Cyclospora cayetanensis from lettuce, herbs and raspberries. International Journal of Food Microbiology. 153, pp. 123-128.

Shields, J.M. and Olson, B.H. (2003). PCR-restriction fragment length polymorphism method for detection of Cyclospora cayetanensis in environmental waters without microscopic confirmation. Applied and Environmental Microbiology. 69, pp. 4662-4669.

Shields, J.M. and Olson, B.H. (2003). Cyclospora cayetanensis: a review of an emerging parasitic coccidian. International Journal for Parasitology. 33, pp. 371-391.

Shlim, D.R., Cohen, M.T., Eaton, M., Rajah, R., Long, E.G. and Ungar, B.L. (1991). An alga-like organism associated with an outbreak of prolonged diarrhea among foreigners in Nepal. The American Journal of Tropical Medicine and Hygiene. 45, pp. 383-389.

Sifuentes-Osorio, J., Porras-Cortés, G., Bendall, R.P., Morales-Villarreal, F., Reyes-Terán, G. and Ruiz-Palacios, G.M. (1995). Cyclospora cayetanensis infection in patients with and without AIDS: biliary disease as another clinical manifestation. Clinical Infectious Diseases. 21, pp. 1092-1097.

Smith, H.V., Paton, C.A., Girdwood, R.W. and Mtambo, M.M. (1996). Cyclospora in nonhuman primates in Gombe Tanzania. The Vetinary Record. 138, pp. 528.

Smith, H.V., Paton, C.A., Mtambo, M.M. and Girdwood, R.W. (1997). Sporulation of Cyclospora sp. oocysts. Applied and Environmental Microbiology. 63, pp. 1631-1632.

Soave, R. (1996). Cyclospora: an overview. Clinical Infectious Diseases. 23, pp. 429-435.

Soave, R., Dubey, J.P., Ramos, L.J. and Tummings, M. (1986). A new intestinal pathogen?. Journal of Clinical Research. 34, pp. 533A.

Soave, R., Herwaldt, B.L. and Relman, D.A. (1998). Cyclospora. Infect Dis Clin N Am. Infectious Disease Clinics of North America. 12, pp. 1-12.

Sterling, C.R. and Ortega, Y.R. (1999). Cyclospora: an enigma worth unraveling. Emerging Infectious Diseases. 5, pp. $48-53$.

Stocks, P.A., Barton, V., Antoine, T., Biagini, G.A., Ward, S.A. and O'Neill, P.M. (2014). Novel inhibitors of the Plasmodium falciparum electron transport chain. Parasitology. 141, pp. 50-65.

Sturbaum, G.D., Ortega, Y.R., Gilman, R.H., Sterling, C.R., Cabrera, L. and Klein, D.A. (1998). Detection of Cyclospora cayetanensis in wastewater. Applied and Environmental Microbiology. 64, pp. 2284-2286. 
Sulaiman, I.M., Ortega, Y., Simpson, S. and Kerdahi, K. (2014). Genetic characterization of human-pathogenic Cyclospora cayetanensis parasites from three endemic regions at the 18S ribosomal RNA locus. Infection, Genetics and Evolution. 22, pp. 229-234.

Sulaiman, I.M., Torres, P., Simpson, S., Kerdahi, K. and Ortega, Y. (2013). Sequence characterization of heat shock protein gene of Cyclospora cayetanensis isolates from Nepal, Mexico, and Peru. Journal of Parasitology. 99, pp. 379-382.

Sun, T., Ilardi, C.F., Asnis, D., Bresciani, A.R., Goldenberg, S., Roberts, B. et al. (1996). Light and electron microscopic identification of Cyclospora species in the small intestine. Evidence of the presence of asexual life cycle in human host. American Journal of Clinical Nutrition. 105, pp. 216-220.

Tandukar, S., Ansari, S., Adhikari, N., Shrestha, A., Gautam, J., Sharma, B. et al. (2013). Intestinal parasitosis in school children of Lalitpur district of Nepal. BMC Research Notes. 6, pp. 449. doi: 10.1186/1756-0500-6-449.

Tang, K., Guo, Y., Zhang, L., Rowe, L.A., Roellig, D.M., Frace, M.A. et al. (2015). Genetic similarities between Cyclospora cayetanensis and cecum-infecting avian Eimeria spp. in apicoplast and mitochondrial genomes. Parasit Vectors. 8, pp. 358. doi: 10.1186/s13071-015-0966-3.

Taniuchi, M., Verweij, J.J., Sethabutr, O., Bodhidatta, L., Garcia, L., Maro, A. et al. (2011). Multiplex polymerase chain reaction method to detect Cyclospora, Cystoisospora, and Microsporidia in stool samples. Diagnostic Microbiology and Infectious Disease. 71, pp. 386-390.

Thima, K., Mori, H., Praevanit, R., Mongkhonmu, S., Waikagul, J. and Watthanakulpanich, D. (2014). Recovery of Cyclospora cayetanensis among asymptomatic rural Thai schoolchildren. Asian Pacific Journal of Tropical Medicine. 7, pp. 119-123.

Thomas, M.K., Murray, R., Flockhart, L., Pintar, K., Pollari, F., Fazil, A. et al. (2013). Estimates of the burden of foodborne illness in Canada for 30 specified pathogens and unspecified agents, Circa 2006. Foodborne Pathogens and Disease. 10, pp. 639-648.

Torres-Slimming, P.A., Mundaca, C.C., Moran, M., Quispe, J., Colina, O., Bacon, D.J. et al. (2006). Outbreak of cyclosporiasis at a naval base in Lima Peru. The American Journal of Tropical Medicine and Hygiene. 75, pp. 546-548.

Tram, N.T., Hoang, L.M., Cam, P.D., Chung, P.T., Fyfe, M.W., Isaac-Renton, J.L. et al. (2008). Cyclospora spp. in herbs and water samples collected from markets and farms in Hanoi, Vietnam. Tropical Medicice and International Health. 13, pp. 1415-1420.

Turgay, N., Yolasigmaz, A., Erdogan, D.D., Zeyrek, F.Y. and Uner, A. (2007). Incidence of cyclosporiasis in patients with gastrointestinal symptoms in western Turkey. Med Sci Monit. 13, pp. CR34 - 39.

Uga, S., Hoa, N.T., Noda, S., Moji, K., Cong, L., Aoki, Y. et al. (2009). Parasite egg contamination of vegetables from a suburban market in Hanoi, Vietnam. Nepal Medical College Journal. 11, pp. 75-78.

Varma, M., Hester, J.D., Schaefer, III, F.W., Ware, M.W. and Lindquist, H.D. (2003). Detection of Cyclospora cayetanensis using a quantitative real-time PCR assay. Journal of Microbiological Methods. 53, pp. 27-36.

Velasquez, J.N., Carnevale, S., Cabrera, M., Kuo, L., Chertcoff, A., Mariano, M. et al. (2004). Cyclospora cayetanensis en pacientes con SIDA y diarrea cronica. Acta Gastroenterol Latinoam. 34, pp. 133-137.

Verdier, R.I., Fitzgerald, D.W., Johnson, Jr, W.D. and Pape, J.W. (2000). Trimethoprim-sulfamethoxazole compared with ciprofloxacin for treatment and prophylaxis of Isospora belli and Cyclospora cayetanensis infection in HIV-infected patients. A randomized, controlled trial. Annals of Internal Medicine. 132, pp. 885-888.

Vesey, G., Slade, J.S., Byrne, M., Shepherd, K. and Fricker, C.R. (1993). A new method for the concentration of Cryptosporidium oocysts from water. Journal of Applied Microbiology. 75, pp. 82-86.

Visvesvara, G.S., Moura, H., Kovacs-Nace, E., Wallace, S. and Eberhard, M.L. (1997). Uniform staining of Cyclospora oocysts in fecal smears by a modified safranin technique with microwave heating. Journal of Clinical Microbiology. 35, pp. 
730-733.

Vuong, T.A., Nguyen, T.T., Klank, L.T., Phung, D.C. and Dalsgaard, A. (2007). Faecal and protozoan parasite contamination of water spinach (Ipomoea aquatica) cultivated in urban wastewater in Phnom Penh, Cambodia. Tropical Medicice and International Health. 12, pp. 73-81.

Wang, K.X., Li, C.P., Wang, J. and Tian, Y. (2002). Cyclospora cayetanensis in Anhui China. World Journal of Gastroenterology. 8, pp. 1144-1148.

Weitzel, T., Wichmann, O., Mühlberger, N., Reuter, B., Hoof, H.D. and Jelinek, T. (2006). Epidemiological and clinical features of travel-associated cryptosporidiosis. Clinical Microbiology and Infection. 12, pp. 921-924.

Wurtz, R.M., Kocka, F.E., Peters, C.S., Weldon-Linne, C.M., Kuritza, A. and Yungbluth, P. (1993). Clinical characteristics of seven cases of diarrhea associated with a novel acid-fast organisms in the stool. Clinical Infectious Diseases. 16, pp. 136-138.

Yai, L.E., Bauab, A.R., Hirschfeld, M.P., de Oliveira, M.L. and Damaceno, J.T. (1997). The first two cases of Cyclospora in dogs, Sao Paulo, Brazil. Revista do Instituto de Medicina Tropical de São Paulo. 39, pp. 177-179.

Zar, F.A., El-Bayoumi, E. and Yungbluth, M.M. (2001). Histologic proof of acalculous cholecystitis due to Cyclospora cayetanensis. Clinical Infectious Diseases. 33, pp. E140-141.

Zerpa, R., Uchima, N. and Huicho, L. (1995). Cyclospora cayetanensis associated with watery diarrhoea in Peruvian patients. Journal of Tropical Medicine and Hygiene. 98, pp. 325-329.

Zhao, G.H., Cong, M.M., Bian, Q.Q., Cheng, W.Y., Wang, R.J., Qi, M. et al. (2013). Molecular characterization of Cyclospora-like organisms from golden snub-nosed monkeys in Qinling Mountain in Shaanxi province, northwestern China. PLoS One. 8, pp. e58216.

Zhou, Y., Lv, B., Wang, Q., Wang, R., Jian, F., Zhang, L. et al. (2011). Prevalence and molecular characterization of Cyclospora cayetanensis, Henan, China. Emerging Infectious Diseases. 17, pp. 1887-1890.

Zimmer, S.M., Schuetz, A.N. and Franco-Paredes, C. (2007). Efficacy of nitazoxanide for cyclosporiasis in patients with sulfa allergy. Clinical Infectious Diseases. 44, pp. 466-467. 